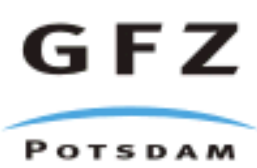

Originally published as:

Lund, S. P., Stoner, J., Channell, J., Lamy, F. (2007): Detailed Paleomagnetic and Rock Magnetic Variability within Three High-Resolution Study Intervals from Site 1233. -

Proceedings of the Ocean Drilling Program, Scientific Results, 202, 1-30

DOI:10.2973/odp.proc.sr.202.212.2007 
Tiedemann, R., Mix, A.C., Richter, C., and Ruddiman, W.F. (Eds.)

Proceedings of the Ocean Drilling Program, Scientific Results Volume 202

\section{Detalled Paleomagnetic and ROCK MAGNETIC VARIABILITY WITHIN THREE HIGH-RESOLUTION STUDY INTERVALS FROM SITE 1233'}

Steve P. Lund, ${ }^{2}$ Joseph Stoner, ${ }^{3}$ James Channell, ${ }^{4}$ and Frank Lamy ${ }^{5}$

\begin{abstract}
We carried out a detailed rock magnetic and paleomagnetic study of deep-sea sediments from selected intervals of Site 1233 in order to assess whether they contain reproducible evidence for submillennial-scale environmental, climatic, and geomagnetic field variability. Three $1.5-\mathrm{m}$ sediment intervals from oxygen isotope Stages 1, 2, and 3 were sampled using continuous U-channels; replicate sediment sequences were collected from two or three holes in each interval to test for reproducibility. Rock magnetic and paleomagnetic measurements were made at 1$\mathrm{cm}$ intervals. Rock magnetic results identify distinctive centennial $(\sim 150-300 \mathrm{yr})$ - and millennial-scale variability that is probably continuous over the entire Site 1233 record. They also show evidence for intermittent multidecadal-scale rock magnetic variability. The rock magnetic variability allows us to modify the meters composite depth (mcd) correlation in each of the three high-resolution intervals to permit correlations between holes at $\sim 5-\mathrm{cm}$ resolution. Paleomagnetic results indicate that there is also a reproducible pattern of paleomagnetic secular variation at the centennial to millennial scale. The centennial-scale variability is dominated by $\sim 5^{\circ}-10^{\circ}$ oscillations in both inclination and declination with an average interval of 200-300 yr. Deconvolution studies and paleomagnetic secular variation (PSV) correlations between holes both suggest that the PSVs are real and not caused by similar-scale rock magnetic variability. The paleomagnetic results also document dis-
\end{abstract}

${ }^{1}$ Lund, S.P., Stoner, J., Channell, J., and Lamy, F., 2007. Detailed paleomagnetic and rock magnetic variability within three highresolution study intervals from Site 1233. In Tiedemann, R., Mix, A.C., Richter, C., and Ruddiman, W.F. (Eds.), Proc. ODP, Sci. Results, 202: College Station, TX (Ocean Drilling Program), 1-30. doi:10.2973/ odp.proc.sr.202.212.2007

${ }^{2}$ Department of Earth Sciences, University of Southern California, Los Angeles CA 90089-0740, USA. slund@usc.edu

${ }^{3}$ School of Oceanic and Atmospheric Sciences, Oregon State University, Corvallis OR 97331-5503, USA.

${ }^{4}$ Department of Geological Sciences, University of Florida, Gainesville FL 32611, USA.

${ }^{5}$ GeoForschungsZentrum,

Telegrafenberg, 14473, Potsdam, Germany.

Initial receipt: 22 March 2005 Acceptance: 23 February 2006 Web publication: 18 January 2007 
S.P. LUND ET AL.

tinctive, larger-amplitude multicentennial- and millennial-scale directional variability that is consistent with preliminary shipboard paleomagnetic studies.

\section{INTRODUCTION}

During Ocean Drilling Program (ODP) Leg 202, a variety of automated, quantitative shipboard measurements were made on the deepsea sediment cores recovered from each site as part of the routine initial scientific analysis (Mix, Tiedemann, Blum, et al., 2003). Some of these measurements were needed while coring progressed in order to develop a complete composite section (splice) among replicate holes from each site. This assured $100 \%$ recovery and sampling of all cored intervals. At Site $1233\left(41.0^{\circ} \mathrm{S}, 74.4^{\circ} \mathrm{W}\right)$, shipboard measurements noted strong variability at the decimeter to meter scale throughout the sediment sequence, even though the sediments appeared to be generally uniform, hemipelagic, terrigenous-rich sediments. Such variability could result from oscillating regional, environmental, or climatic conditions.

Initial shipboard estimates of sediment accumulation rates for Site 1233 were determined in three ways (Mix, Tiedemann, Blum, et al., 2003): (1) the Holocene sediments from site survey Core GeoB-3313-1 $\left(41.0^{\circ} \mathrm{S}, 74.4^{\circ} \mathrm{W}\right)$ (Lamy et al., 2002), which has an accelerator mass spectrometry (AMS) radiocarbon chronology (AMS radiocarbon dates on carbonate microfossils), were correlated with the uppermost sediment sequence from Site 1233 using magnetic susceptibility variations; (2) a distinctive magnetic field excursion was identified at $\sim 68$ meters composite depth (mcd), which was correlated to the Laschamp Excursion ( 41,000 cal. yr before present [BP]); and (3) an initial geomagnetic paleointensity record was developed using shipboard measurements of the sediment natural remanent magnetization (NRM) normalized by magnetic susceptibility; this record was then correlated with a number of other dated paleointensity records from around the world. All three chronostratigraphic estimates suggested that Site 1233 has an average sediment accumulation rate of nearly $150 \mathrm{~cm} / \mathrm{k}$.y. for the last $\sim 70,000$ yr. On that basis, the decimeter- to meter-scale variability should convert to multidecadal- to centennial-scale variability.

Shipboard discussions focused on whether Site 1233 might reproducibly preserve such high-frequency environmental/climatic variability. It is extremely rare to find long marine records of submillennial-scale environmental/climatic variability, particularly in the Southern Hemisphere. A series of studies were formulated to evaluate this potential. Three intervals were chosen, one each in oxygen isotope Stages 1, 2, and 3 . Each chosen interval would be $1.5 \mathrm{~m}$ in length, and a series of very high resolution $(\sim 1-2 \mathrm{~cm})$ measurements would be made on the sediments from multiple holes in each interval to test for reproducibility. This paper summarizes the rock magnetic and paleomagnetic variability in the three high-resolution intervals. The focus of this study is to determine whether distinctive and reproducible evidence for submillennial-scale environmental/climatic or geomagnetic field variability can be recovered routinely at Site 1233 . 
S.P. LUND ET AL.

STAGE 1 (HOLOCENE) HIGH-RESOLUTION INTERVAL

The Stage 1 high-resolution interval is located from 1.5 to 3.0 mcd. Four AMS radiocarbon dates from a neighboring piston core (Lamy et al., 2002; Mix, Tiedemann, Blum, et al. 2003), two of which are shown in Figures F1 and F2, bracket this interval. These dates estimate that the Stage 1 high-resolution interval extends from $\sim 900$ to $2000 \mathrm{cal}$. yr BP with an average sediment accumulation rate of $144 \mathrm{~cm} / \mathrm{k} . \mathrm{y}$.

Two core intervals from Holes $1233 \mathrm{~B}$ and 1233D were sampled "off splice," that is using sediments not part of the Site 1233 composite section (splice). We were also able to study the entire splice section for Site 1233 as part of our normal paleomagnetic studies. Thus, we also have paleomagnetic and rock magnetic data for Hole 1233C in this high-resolution interval.

All of these intervals were sampled at the ODP Gulf Coast Core Repository (College Station, Texas) as continuous sediment columns using U-channels. U-channels are fairly rigid $2 \mathrm{~cm} \times 2 \mathrm{~cm}$ square cross-section plastic tubes, which are as long as the individual core segments, usually $150 \mathrm{~cm}$. The U-channels have one open side, which is pushed into the flat surface of a split sediment core and then carved out to recover a 2 $\mathrm{cm} \times 2 \mathrm{~cm} \times \sim 150 \mathrm{~cm}$ column of sediment. The U-channel open side is then capped to produce a long minicore of sediment that is protected by the U-channel and its plastic cap. All U-channels collected at the repository were measured using an automated $2 \mathrm{G}$ cryogenic magnetometer (cryomag) and automated magnetic susceptibility system at the University of Florida (USA). See the "Appendix," p. 12, for a detailed breakdown of core segments and depths sampled for this study.

\section{Methods}

The NRM of all U-channels was initially measured and then sequentially demagnetized and remeasured in alternating fields (AF) from 25 to $100 \mathrm{mT}$. An artificial anhysteretic remanent magnetization (ARM) was then applied to each U-channel using a 0.05-mT steady field and 100-mT AF; the initial ARM was measured and then demagnetized/measured sequentially using the same sequence of steps as the NRM. Next, each U-channel was given a saturation isothermal remanent magnetization (SIRM) using a pulsed steady magnetic field of $950 \mathrm{mT}$; the initial SIRM was measured and then demagnetized/measured sequentially using the same sequence of steps. At some point in the measurement process, usually before initial NRM measurement, the magnetic susceptibility $(\chi)$ of each U-channel was also measured. In all cases, the measurements were made at a $1-\mathrm{cm}$ interval, although the instrument response functions of the cryomag and susceptibility system are several centimeters wide.

\section{Rock Magnetic Results}

The overall intensities of the NRM, ARM, SIRM, and $\chi$ vary by less than a factor of two, indicating that the sediment magnetic characteristics are quite homogenous. This is corroborated by the homogenous visual character of the sediments (Mix, Tiedemann, Blum, et al., 2003). Even so, there is noticeable intensity variability in each of these parameters that is easily correlated between holes, as illustrated in Figures F1
F1. Stage 1 magnetic susceptibility, p. 13.

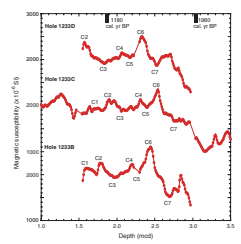

F2. Stage 1 initial ARM, p. 14.

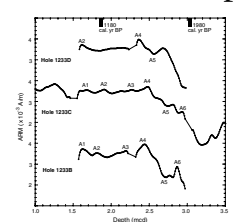


S.P. LUND ET AL.

$(\chi)$ and F2 (ARM). All four intensity parameters display a distinctive $\sim 30$-cm $(\sim 200-y r)$ oscillation in intensity throughout the studied interval as well as evidence of longer $1+\mathrm{m}$ (millennial-scale) variability. $\chi$ (Fig. F1) and NRM also show evidence for a more subtle and intermittent $\sim 10-\mathrm{cm}(\sim 70-\mathrm{yr})$ oscillation in intensity as well. The $\chi$, ARM, and SIRM intensity variations are attributable to either varying concentrations/grain size of ferromagnetic minerals (assumed to be magnetite derived from the Andes) and paramagnetic iron-bearing minerals in the clastic fraction or else varying dilution of the clastic fraction by organic materials (organic carbon, biogenic carbonate, or silica). Either of these processes must be due to subtly varying regional environmental conditions. The NRM intensity variability is more complicated for it can be influenced by these environmental variations and by variations in local geomagnetic field strength.

\section{Stratigraphic Correlation of Rock Magnetic Parameters}

Figures F1 and F2 document the distinctive lithostratigraphic correlation of a number of rock magnetic features among the three Stage 1 high-resolution study holes at Site 1233. The depth equivalences of 26 rock magnetic features $(\chi, N R M, A R M$, and SIRM) from Hole 1233B and 21 rock magnetic features from Hole 1233D relative to Hole 1233C are shown in Figure F3 (solid circles $=$ Hole 1233B, solid squares $=$ Hole 1233D). If all of the correlatable features were exactly equivalent in depth, then all of the correlation points would fall on the straight diagonal line in Figure F3. That is the ideal if the mcd stratigraphy developed on board the ship (Mix, Tiedemann, Blum, et al., 2003) was exactly correct. In reality, however, the mcd system used tie points between holes that were stratigraphically spaced several meters apart. Thus, small-scale stratigraphic variations between holes could not be corrected by the mcd stratigraphy. The lines (20-cm boxcar smoothing of the rock magnetic correlations) connecting the solid circles and squares in Figure F3 represent a further modification of the mcd stratigraphy that best indicates the centimeter-scale correlation of Holes 1233B and 1233D relative to Hole 1233C, which is part of the splice. These correlations represent our best estimate of the relative lithostratigraphic (and chronostratigraphic) framework for the Stage 1 high-resolution interval and would facilitate any future comparison of environmental variations recovered from the Stage 1 high-resolution study.

\section{Paleomagnetic Results}

Figures F4 and F5 summarize our new U-channel paleomagnetic measurements (1-cm interval, solid circles) and our preliminary shipboard paleomagnetic measurements $(5-\mathrm{cm}$ interval, open diamonds) made on all of the Stage 1 high-resolution intervals. Both paleomagnetic data sets are plotted as NRMs after 25-mT AF demagnetization to facilitate comparison between them. (The U-channel 25-mT paleomagnetic data are not significantly different from component remanences determined from principal-component fitting of the U-channel NRM results between 30 and $90 \mathrm{mT}$. Moisture and density [MAD] values are typically less than $3^{\circ}$.) The dashed lines indicate a seven-point running average of the shipboard results that was used by Mix, Tiedemann, Blum, et al. (2003) to develop an initial paleomagnetic secular variation
F3. Rock magnetic correlations with Hole 1233C, p. 15.

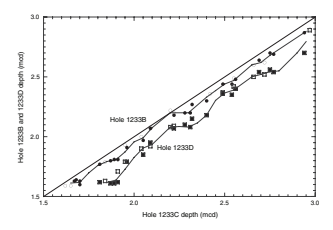

F4. Stage 1 paleomagnetic inclination, p. 16.

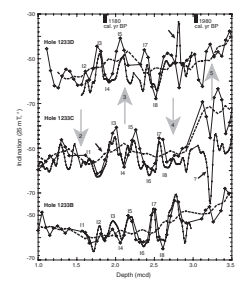

F5. Stage 1 paleomagnetic declination, p. 17.

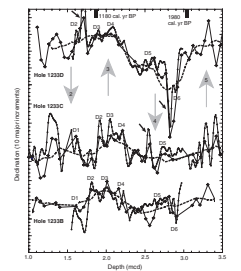


S.P. LUND ET AL.

(PSV) record for Site 1233 and correlate it with published Holocene lake sediment PSV records from Argentina (Creer et al., 1983; Gogorza et al., 2000). Lund et al. (this volume) have identified $>200$ distinctive paleomagnetic inclination and declination features in the shipboard measurements that are correlatable between holes at Site 1233 and with similar PSV results from Site 1234, $>500 \mathrm{~km}$ away. Inclination and declination features 2-5 from Lund et al. (this volume) are identified by numbered gray arrows in Figures F4 and F5. These features are also discernable in the Argentine lake sediment PSV records (Mix, Tiedemann, Blum, et al., 2003). The shipboard-derived inclination and declination features indicated by the dashed curves and gray arrows have an oscillation of $\sim 150 \mathrm{~cm}$ or $\sim 1000 \mathrm{yr}$.

The U-channel paleomagnetic results show the same long-term directional trends noted in the preliminary shipboard measurements. They also show reproducible evidence for higher-frequency directional variability. The U-channel paleomagnetic results show correlatable inclination features I1-I8 in Figure F4 and similar declination features D1-D6 in Figure $\mathbf{F} 5$ that have an $\sim 30$-cm oscillation, which translates into durations of $\sim 200 \mathrm{yr}$. The preliminary shipboard measurements also show evidence for these higher-frequency variations in inclination and declination. But limited demagnetization $(<25 \mathrm{mT})$ of the shipboard measurements, lower sampling resolution $(5 \mathrm{~cm})$, and the fact that shipboard measurements were made on core halves (with potentially disturbed core margins) rather than U-channels collected from pristine core interiors (split faces) made the reality of such variations suspect. Our higher-quality U-channel paleomagnetic measurements, however, show that these higher-frequency directional variations are reproducible.

The U-channel paleomagnetic measurements have a few potential problems indicated by arrows in Figures F4 and F5. Hole 1233D has an inclination low near 2.8 mcd that is not present in the other holes or even its own shipboard measurements; Hole 1233C is missing inclination feature I2 near $1.8 \mathrm{mcd}$; Hole 1233C has higher inclinations from 3.1 to 3.5 mcd than its shipboard measurements with an anomalous inclination high near 3.3 mcd; Hole 1233D declination feature D2 is anomalously large in amplitude and has an extra declination westerly swing near 2.9 mcd not present in the other holes; and Hole 1233C has an extra easterly declination swing near $2.5 \mathrm{mcd}$ not present in the other holes. Even with these complications, it is apparent that the Uchannel paleomagnetic directions identify a reproducible oscillation throughout this interval with an 200 -yr duration.

We can also assess the veracity of our paleomagnetic correlations between Holes 1233B, 1233C, and 1233D by comparing them with the rock magnetic correlations. The paleomagnetic correlations noted above in Figures F4 and F5 are identified by open circles (Hole 1233B vs. Hole 1233C) and open squares (Hole 1233D vs. Hole 1233C) in Figure F3. It is apparent that the paleomagnetic correlations are not significantly different from the rock magnetic correlations. This indicates that the Stage 1 centennial-scale paleomagnetic variability is reproducible (and synchronous on a relative scale) among the holes of Site 1233.

\section{STAGE 2 HIGH-RESOLUTION INTERVAL}

The Stage 2 high-resolution interval is located from 22.0 to 23.5 mcd. Twenty AMS radiocarbon dates have been recovered from the Pleistocene sediments of Site 1233 by Lamy et al. (2004). Two radiocarbon 
S.P. LUND ET AL.

dates (20.22 mcd: 13,620 cal. yr BP, 25.10 mcd: 17,240 cal. yr BP) bracket the Stage 2 high-resolution interval. They provide an estimated time interval of $\sim 15,000-16,000$ cal. yr BP with an average sediment accumulation rate of $135 \mathrm{~cm} / \mathrm{k} . \mathrm{y}$. Three core intervals from Holes 1233B, $1233 \mathrm{C}$, and 1233E were sampled for this study.

\section{Rock Magnetic Results}

We measured $\chi$ and the NRM and ARM intensities (initial remanence and remanence after stepwise AF demagnetization up to $100 \mathrm{mT}$ ) at a 1$\mathrm{cm}$ interval. All of the rock magnetic parameters vary by less than a factor of two in this interval, indicating a generally homogenous sedimentary interval with only subtle lithostratigraphic variations. This is consistent with the visual core logs available in Mix, Tiedemann, Blum, et al. (2003). Even so, there is a noticeable correlation between holes in the intensity variability for each of these parameters as illustrated in Figures F6 $(\chi)$ and F7 (ARM). All three intensity parameters display a significant 20 - to $30-\mathrm{cm}(\sim 150-\mathrm{yr})$ oscillation in intensity throughout the studied interval. $\chi$ (Fig. F6) and NRM also show evidence for a more subtle and intermittent $5-$ to $10-\mathrm{cm}(\sim 70-\mathrm{yr})$ oscillation in intensity as well. As in Stage 1, we associate the $\chi$ and ARM intensity variations with environmental changes caused by either varying concentrations of ferromagnetic minerals (assumed to be magnetite derived from the Andes) and paramagnetic iron-bearing minerals in the clastic fraction or else varying dilution of the clastic fraction by organic materials (organic carbon, biogenic carbonate, or silica).

\section{Stratigraphic Correlation of Rock Magnetic Parameters}

Figures F6 and F7 indicate the strong correlation of rock magnetic features among the three Stage 2 high-resolution study holes at Site 1233. Figure $\mathbf{F} 8$ displays the depth equivalences of 21 rock magnetic features $(\chi, \mathrm{NRM}$, and ARM) from Hole 1233B (solid circles) and 26 features from Hole 1233E (solid squares) relative to Hole 1233C. If all of the correlatable features were exactly equivalent in depth, then all of the correlation points would fall on the straight diagonal line in Figure F8. The lines (20-cm boxcar running average) connecting the solid circles and squares in Figure F8 represent a further modification of the mcd stratigraphy that best indicates the centimeter-scale correlation of Holes $1233 \mathrm{~B}$ and $1233 \mathrm{E}$ relative to Hole $1233 \mathrm{C}$, which is part of the splice. Those correlations would facilitate any future comparison of environmental variations recovered from the Stage 2 high-resolution study.

\section{Paleomagnetic Results}

Figures F9 and F10 summarize our new U-channel paleomagnetic measurements (1-cm interval, solid circles) and the preliminary shipboard paleomagnetic measurements $(5-\mathrm{cm}$ interval, open diamonds) made on all of the Stage 2 high-resolution intervals. The dashed lines indicate a seven-point running average of the shipboard results. Inclination features 22-25 and declination features 17-19 from Lund et al. (this volume) are indicated by numbered gray arrows in Figures F9 and F10. These shipboard data-derived directional features have an oscillation of $\sim 150 \mathrm{~cm}$ or $\sim 1000 \mathrm{yr}$.
F6. Stage 2 magnetic susceptibility, p. 18.

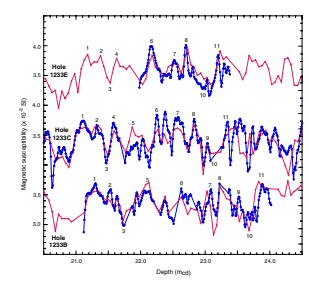

F7. Stage 2 initial ARM, p. 19.

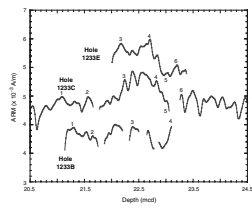

F8. Rock magnetic features correlatable with Hole 1233C, p. 20.

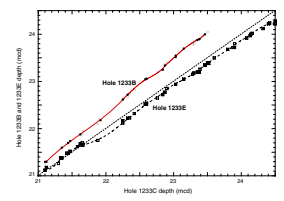

F9. Stage 2 paleomagnetic inclination, p. 21.

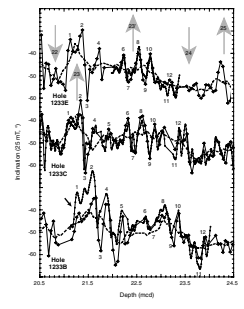

F10. Stage 2 paleomagnetic declination, p. 22.

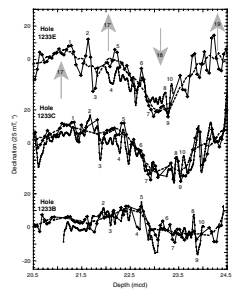


S.P. LUND ET AL.

The U-channel paleomagnetic results show the same long-term directional trends noted in the preliminary shipboard measurements. They also show reproducible evidence for higher-frequency directional variability. The U-channel paleomagnetic results show correlatable inclination features 1-12 in Figure F9 and similar declination features 1-10 in Figure F10 that have an $\sim 30$-cm oscillation, which translates into durations of $\sim 150 \mathrm{yr}$. The preliminary shipboard measurements also show evidence for these higher-frequency variations in inclination and declination. But limited demagnetization $(<25 \mathrm{mT})$ of the shipboard measurements, lower sampling resolution $(5 \mathrm{~cm})$, and the fact that shipboard measurements were made on core halves (with potentially disturbed core margins) rather than U-channels collected from pristine core interiors (split faces) made the reality of such variations suspect. Our higher-quality U-channel paleomagnetic measurements, however, show that these higher-frequency directional variations are reproducible. The U-channel paleomagnetic measurements do, however, have one anomalous interval of $10^{\circ}$ anomalously shallow inclinations from $\sim 21.2$ to $22.2 \mathrm{mcd}$ in the Hole 1233B U-channel measurements (arrow in Figure F9) relative to the Hole 1233B shipboard measurements and the Hole 1233C U-channel measurements.

The correlatable inclination and declination features noted between Holes 1233B and 1233E vs. Hole 1233C in Figures F9 and F10 are indicated by open symbols in Figure F8. As in the Stage 1 high-resolution interval, the Stage 2 paleomagnetic correlations are consistent with the rock magnetic correlations, indicating that the Stage 2 centennial-scale paleomagnetic field variability is reproducible (and synchronous on a relative scale) among the holes of Site 1233.

\section{STAGE 3 HIGH-RESOLUTION INTERVAL}

The Stage 3 high-resolution interval is located from 56.3 to 57.8 mcd. Three radiocarbon dates $(55.02$ mcd: 32,340 cal. yr BP, 59.03 mcd: 36,360 cal. yr BP, and 62.50 mcd: 39,050 cal. yr BP) from Lamy et al. (2004) bracket this interval. The dates suggest a time interval from $\sim 33,600$ to $\sim 35,100$ cal. yr BP and an average sediment accumulation rate of $114 \mathrm{~cm} / \mathrm{k} . \mathrm{y}$. Cores from Hole $1233 \mathrm{~B}$ and Hole $1233 \mathrm{D}$ were sampled for this study.

\section{Rock Magnetic Results}

We measured $\chi$ and the NRM and ARM intensities (initial remanence and remanence after stepwise AF demagnetization up to $100 \mathrm{mT}$ ) at a 1$\mathrm{cm}$ interval. Overall, the intensities vary by less than a factor of two, just like the other two high-resolution intervals. There is a significant correlation between holes in the intensity variability for each of these parameters as illustrated in Figures F11 $(\chi)$ and F12 (ARM). All three intensity parameters display a subtle, but noticeable, $\sim 20-\mathrm{cm}(\sim 200-\mathrm{yr})$ oscillation in intensity throughout the studied interval. $\chi$ (Fig. F11) and NRM also show evidence for a more intermittent $\sim 10$-cm $(\sim 100-y r)$ oscillation in intensity as well. As in Stages 1 and 2, we associate the $\chi$ and ARM intensity variations with environmental changes caused by either varying concentrations of ferromagnetic minerals (assumed to be magnetite derived from the Andes) and paramagnetic iron-bearing minerals in the clastic fraction or else varying dilution of the clastic fraction by organic materials (organic carbon, biogenic carbonate, or silica).
F11. Stage 3 magnetic susceptibility, p. 23.

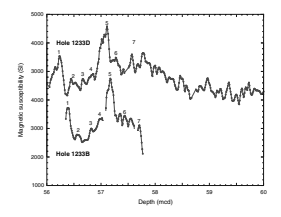

F12. Stage 3 initial ARM, p. 24.

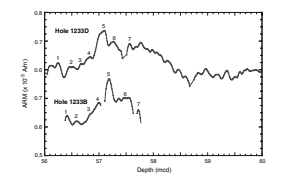


S.P. LUND ET AL.

\section{Stratigraphic Correlation of Magnetic Parameters}

Figures F11 and F12 indicate the significant correlation of rock magnetic features between the two Stage 3 high-resolution study holes at Site 1233. The depth equivalence of 18 of the $\chi$, NRM, and ARM features relative to Hole 1233D is shown in Figure F13. If all of the correlatable features were exactly equivalent in depth, then all of the correlation points (solid circles) for Hole 1233B would fall on the straight diagonal line in Figure F13. The solid line (20-cm boxcar running average) connecting the solid circles in Figure F13 is not on the straight diagonal line, indicating that the mcd stratigraphy is not exact. The solid line represents a further modification of the mcd stratigraphy that best indicates the centimeter-scale correlation of Hole 1233B relative to Hole $1233 \mathrm{D}$, which is part of the splice. Those correlations would facilitate any future comparison of environmental variations recovered from the Stage 3 high-resolution study.

\section{Paleomagnetic Results}

Figures F14 and F15 summarize our new U-channel measurements (1-cm interval, solid circles) and the preliminary shipboard paleomagnetic measurements (5-cm interval, open diamonds) made on both of the Stage 3 high-resolution intervals. The dashed lines indicate a sevenpoint running average of the shipboard results. Inclination features 4750 and declination features $42-44$, defined by Lund et al. (this volume), are identified by numbered gray arrows in Figures F14 and F15. Declination feature 43 is at the center of a magnetic field excursion, named Excursion $3 \alpha$ by Lund et al. (this volume) for its placement as the youngest observed excursion in Stage 3. The shipboard-derived inclination and declination features indicated by the dashed curves and gray arrows have an oscillation of $\sim 100 \mathrm{~cm}$ or $\sim 1000 \mathrm{yr}$.

The U-channel paleomagnetic results show the same long-term directional trends noted in the preliminary shipboard measurements. They also show reproducible evidence for higher-frequency directional variability. The U-channel paleomagnetic results show correlatable inclination features 1-10 in Figure F14 and similar declination features 1-8 in Figure F15 that have an $\sim 20$-cm oscillation, which translates into durations of $\sim 200$ yr. The preliminary shipboard measurements also show evidence for these higher-frequency variations in inclination and declination. But limited demagnetization $(<25 \mathrm{mT})$ of the shipboard measurements, lower sampling resolution $(5 \mathrm{~cm})$, and the fact that shipboard measurements were made on core halves (with potentially disturbed core margins) rather than U-channels collected from pristine core interiors (split faces) made the reality of such variations suspect. Our higher-quality U-channel paleomagnetic measurements, however, show that these higher-frequency directional variations are reproducible. As in the other high-resolution intervals, the inclination and declination features in Holes 1233B and 1233D (open circles in Fig. F13) have the same correlation as the rock magnetic parameters indicating the reproducible (and synchronous on a relative scale) pattern of the centennial-scale PSV at Site 1233.
F13. Correlatable rock magnetic features between Cores 1233D and 1233B, p. 25.

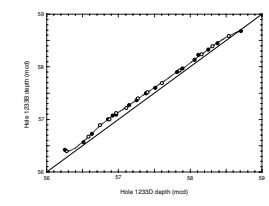

F14. Stage 3 paleomagnetic inclination, p. 26.

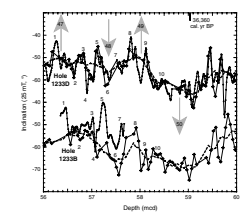

F15. Stage 3 paleomagnetic declination, p. 27.

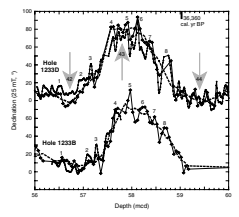


S.P. LUND ET AL.

\section{DECONVOLUTION OF THE U-CHANNEL PALEOMAGNETIC RESULTS}

The paleomagnetic results presented herein were measured using a 2G Enterprises pass-through cryomagnetometer. Such systems are ideally suited for measuring long sediment sequences with high resolution in an automated mode (e.g., Channell, 1999; Stoner et al., 2003). One shortcoming of such systems relative to single discrete-sample measurement systems, however, is that the pass-through pick-up coils average data over a finite interval ( $10 \mathrm{~cm}$ in case of the Florida system-Gaussian shape with a 4.5 -cm width at $1 / 2$ height). This causes some degree of measurement smoothing, which can become a problem occasionally when narrow intervals of anomalously strong or weak material may bias the integrated measurements. Oda and Shibuya $(1996,1998)$ developed a general mathematical procedure for deconvolving the passthrough magnetometer output measurements to correct for the pick-up coil integration and the effects of narrow intervals of anomalous intensity. Guyodo et al. (2002) applied that procedure to the specific configuration of the University of Florida pass-through cryomagnetometer and developed a special deconvolution protocol. We used that protocol to test the quality of the U-channel paleomagnetic measurements (25-mT AF demagnetization) shown in Figures F4, F5, F9, F10, F14, and F15.

Figures F16, F17, and F18 show a comparison of our U-channel paleomagnetic results with results after deconvolution. We deconvolved the original 25-mT paleomagnetic results to reconstruct what the results would have been if each $1-\mathrm{cm}$ interval of the U-channel had been measured individually. It is clear for each of the high-resolution comparison intervals that the $\mathrm{U}$-channel paleomagnetic results presented above are reproduced by the deconvolved data. In particular, the deconvolved results do reproduce the $\sim 10$ - to 20 -cm centennial-scale variability that we discussed above for all three high-resolution intervals. The deconvolved data do also display some $\sim 1$ - to 2 -cm high-frequency variability (arrows indicate selected examples in Figs. F16, F17, and F18), which we think are an artifact of fine-scale sediment variability. We also deconvolved each of the AF demagnetization steps up to $100 \mathrm{mT}$ and recovered a component magnetization using the deconvolved data principal component analysis. In almost all intervals, that deconvolved component magnetization is not significantly different from the component magnetization determined for the original data or the $25-\mathrm{mT}$ results that we have plotted.

\section{DISCUSSION AND CONCLUSIONS}

We carried out a detailed paleomagnetic and rock magnetic study of deep-sea sediments from Site 1233 in order to assess whether these sediments contain reproducible evidence for centennial-scale environmental, climatic, and geomagnetic field variability. Three $1.5-\mathrm{m}$ intervals within oxygen isotope Stages 1, 2, and 3 were sampled using continuous U-channels. Equivalent sediments were collected from two or three holes to test for reproducibility.

Overall, the rock magnetic variability is quite subtle, varying by less than a factor of two in any high-resolution interval. This is consistent with the homogenous visual character of the sediment. Even so, the rock magnetic data indicate a routine and distinctive variability at both
F16. Comparison of Stage $1 \mathrm{U}$ channel paleomagnetic results, p. 28.

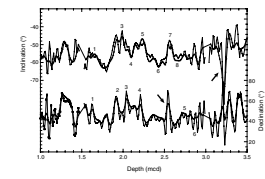

F17. Comparison of Stage $2 \mathrm{U}$ channel paleomagnetic results, p. 29.

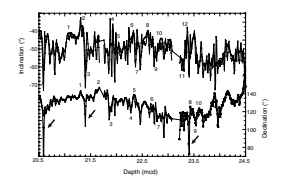

F18. Comparison of Stage $3 \mathrm{U}$ channel paleomagnetic results, p. 30.

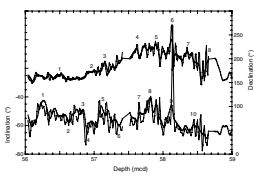


S.P. LUND ET AL.

the centennial and millennial scale. The centennial-scale variability ranges from $\sim 150$ to $300 \mathrm{yr}$ in duration, but it is not clear whether there is a significant difference in frequency between Stage 1 (Holocene) and Stages 2 and 3 (Pleistocene). This variability undoubtedly represents regional variations in environmental or climatic conditions.

Even though all three high-resolution intervals display distinctive centennial-scale environmental variability, the shipboard-derived composite stratigraphy (mcd) is not precise enough to permit correlation of the holes at a centennial-scale resolution. We have developed a modification to the mcd stratigraphy in each of the three high-resolution intervals that should permit correlations between holes at $\sim 5-\mathrm{cm}$ resolution. With this correlation scheme, one should be able to assess reproducibility of environmental features down to the multidecadal scale.

The paleomagnetic results indicate that there is a reproducible pattern of paleomagnetic secular variation at both the centennial scale and millennial scale. The centennial-scale variability is dominated by an $\sim 5^{\circ}-10^{\circ}$ oscillation in both inclination and declination with an average period of 200-300 yr. Thompson and Barraclough (1982) have shown that there are limited regions (e.g., Northern Europe and South Indian Ocean) where such high-frequency PSV is apparent historically. But there is no significant paleomagnetic evidence that such historical behavior persists into prehistoric times in any region.

Interpretation of the centennial-scale PSV variability is further complicated by the observation that there is a similar scale of variability in the rock magnetic properties, due to variations in regional environmental conditions. The PSV deconvolution studies suggest that such rock magnetic variations are not the cause of the observed PSV variations. This is also corroborated by our ability to correlate the centennial-scale PSV between holes at Site 1233. It is tempting to offer that this 200300 PSV oscillation is real. But we cannot be certain of this without replicating this variability at some more distant location. The prospect exists to replicate this variability with future paleomagnetic studies from the same region.

At longer multicentennial and millennial timescales, it is clear that the U-channel measurements provide a high-resolution reproducible record of paleomagnetic field variability that is also corroborated by the preliminary shipboard paleomagnetic studies summarized in Mix, Tiedemann, Blum, et al. (2003) and Lund et al. (this volume). However, the U-channel measurements provide much higher resolution for detailed PSV studies. Site 1233 has the potential (in conjunction with data from Sites 1234 and 1235) to provide the highest-resolution record of PSV ever recovered from the Southern Hemisphere.

\section{ACKNOWLEDGMENTS}

The authors thank the Ocean Drilling Program (ODP), the scientific party and crew of the JOIDES Resolution, and the ODP editorial staff for their assistance in this project. This research used samples and/or data provided by the Ocean Drilling Program (ODP). ODP is sponsored by the U.S. National Science Foundation (NSF) and participating countries under management of Joint Oceanographic Institution (JOI), Inc. This work was partially funded by the Joint Oceanographic Institutions (JOI). 


\section{REFERENCES}

Channell, J.E.T., 1999. Geomagnetic paleointensity and directional secular variation at Ocean Drilling Program (ODP) Site 984 (Bjorn Drift) since 500 ka: comparisons with ODP Site 983 (Gardar Drift). J. Geophys. Res., 104:22937-22951. doi:10.1029/ 1999JB900223

Creer, K., Valencio, D., Sinito, A., Tucholka, P., and Vilas, J., 1983. Geomagnetic secular variations $0-14,000 \mathrm{yr} \mathrm{BP}$ as recorded by lake sediments from Argentina. Geophys. J. R. Astron. Soc., 74:199-221.

Gogorza, C.S.G., Sinito, A.M., Vilas, J.F., Creer, K.M., and Nunez, H., 2000. Geomagnetic secular variations over the last 6500 years as recorded by sediments from the lakes of south Argentina. Geophys. J. Int., 143:787-798. doi:10.1046/j.1365246X.2000.00277.X

Guyodo, Y., Channell, J.E.T., and Thomas, R.G., 2002. Deconvolution of U-channel paleomagnetic data near geomagnetic reversals and short events. Geophys. Res. Lett., 29:1845. doi:10.1029/2002GL014927

Lamy, F., Kaiser, J., Ninnemann, U., Hebbeln, D., Arz, H.W., and Stoner, J., 2004. Antarctic timing of surface water changes off Chile and Patagonian ice sheet response. Science, 304:1959-1962. doi:10.1126/science.1097863

Lamy, F., Rühlemann, C., Hebbeln, D., and Wefer, G., 2002. High- and low-latitude climate control on the position of the southern Peru-Chile Current during the Holocene. Paleoceanography, 17. doi:10.1029/2001PA000727

Mix, A.C., Tiedemann, R., Blum, P., et al., 2003. Proc. ODP, Init. Repts., 202: College Station, TX (Ocean Drilling Program). doi:10.2973/odp.proc.ir.202.2003

Oda, H., and Shibuya, H., 1996. Deconvolution of long-core paleomagnetic data of Ocean Drilling Program by Akaike's Bayesian Information Criterion minimization. J. Geophys. Res., 101:2815-2834. doi:10.1029/95JB02811

Oda, H., and Shibuya, H., 1998. An improvement in ABIC-minimizing deconvolution for continuously measured magnetic remanence data. Earth Planets Space, 50:1522.

Stoner, J.S., Channell, J.E.T., Hodell, D.A., and Charles, C.D., 2003. A 580 kyr paleomagnetic record from the sub-Antarctic South Atlantic (Ocean Drilling Program Site 1089). J. Geophys. Res., 108. doi:10.1029/2001JB001390

Thompson, R., and Barraclough, D.R., 1982. Geomagnetic secular variation based on spherical harmonic and cross validation analyses of historical and archaeomagnetic data. J. Geomag. Geoelectr., 34:245-263. 


\section{APPENDIX}

\section{Intervals Sampled for This Study}

\section{Stage 1 (1.5-3.0 mcd)}

Section 202-1233B-1H-2 (1.51-3.01 mcd). Data extend from 1.55$2.97 \mathrm{mcd}$.

Sections 202-1233D-2H-1 through 2H-2 (1.52-3.02 mcd). The lowermost $75 \mathrm{~cm}$ of Section $2 \mathrm{H}-1$ and uppermost $75 \mathrm{~cm}$ of Section $2 \mathrm{H}-2$ were sampled. Data extend from 1.56 to 2.98 mcd with a data gap at $2.27 \pm$ 0.04 mcd (segment boundary).

Sections $202-1233 \mathrm{C}-1 \mathrm{H}-1$ through $1 \mathrm{H}-3$ (0.00-4.22 mcd, splice interval). Data extend from 0.04 to $4.22 \mathrm{mcd}$ with data gaps at $1.51 \pm 0.04$ and $3.02 \pm 0.04$ mcd (segment boundaries).

\section{Stage 2 (22.0-23.5 mcd)}

Sections 202-1233B-2H-4 through 2H-5 (21.06-24.07 mcd). Data extend from 21.12 to 24.02 mcd with data gaps at $22.57 \pm 0.05$ (segment boundary), $21.8 \pm 0.05,22.25 \pm 5,22.83 \pm 4$, and $23.29 \pm 0.06$ mcd (sediment gaps).

Section 202-1233E-3H-2 (21.93-23.43 mcd). Data extend from 21.98 to $23.38 \mathrm{mcd}$.

Sections 202-1233C-3H-2 through 3H-5 (20.31-26.19 mcd, splice interval). Data extend from 20.36 to 26.19 mcd with data gaps at $21.72 \pm$ $0.04,23.21 \pm 0.04$, and $24.69 \pm 0.04$ mcd (segment boundaries).

\section{Stage 3 (56.31-57.81 $\mathrm{mcd})$}

Section 202-1233B-5H-5 (56.31-57.81 mcd). Data extend from 56.35 to $57.77 \mathrm{mcd}$.

Sections 202-1233D-7H-2 through 7H-6 (56.13-62.74 mcd, splice interval). Data extend from 56.13 to 62.74 mcd with data gaps at $57.47 \pm$ $0.04,58.71 \pm 0.04,60.21 \pm 0.05,61.64 \pm 0.05$ (all segment boundaries), and $60.81 \pm 0.03$ mcd (sediment gap). 
S.P. LUND ET AL.

Paleomagnetic and Rock Magnetic Variability

Figure F1. Stage 1 high-resolution interval 1-cm U-channel magnetic susceptibility measurements. Selected correlatable centennial-scale features are labeled $\mathrm{C} 1-\mathrm{C} 7$. mcd $=$ meters composite depth $\mathrm{BP}=$ before present.

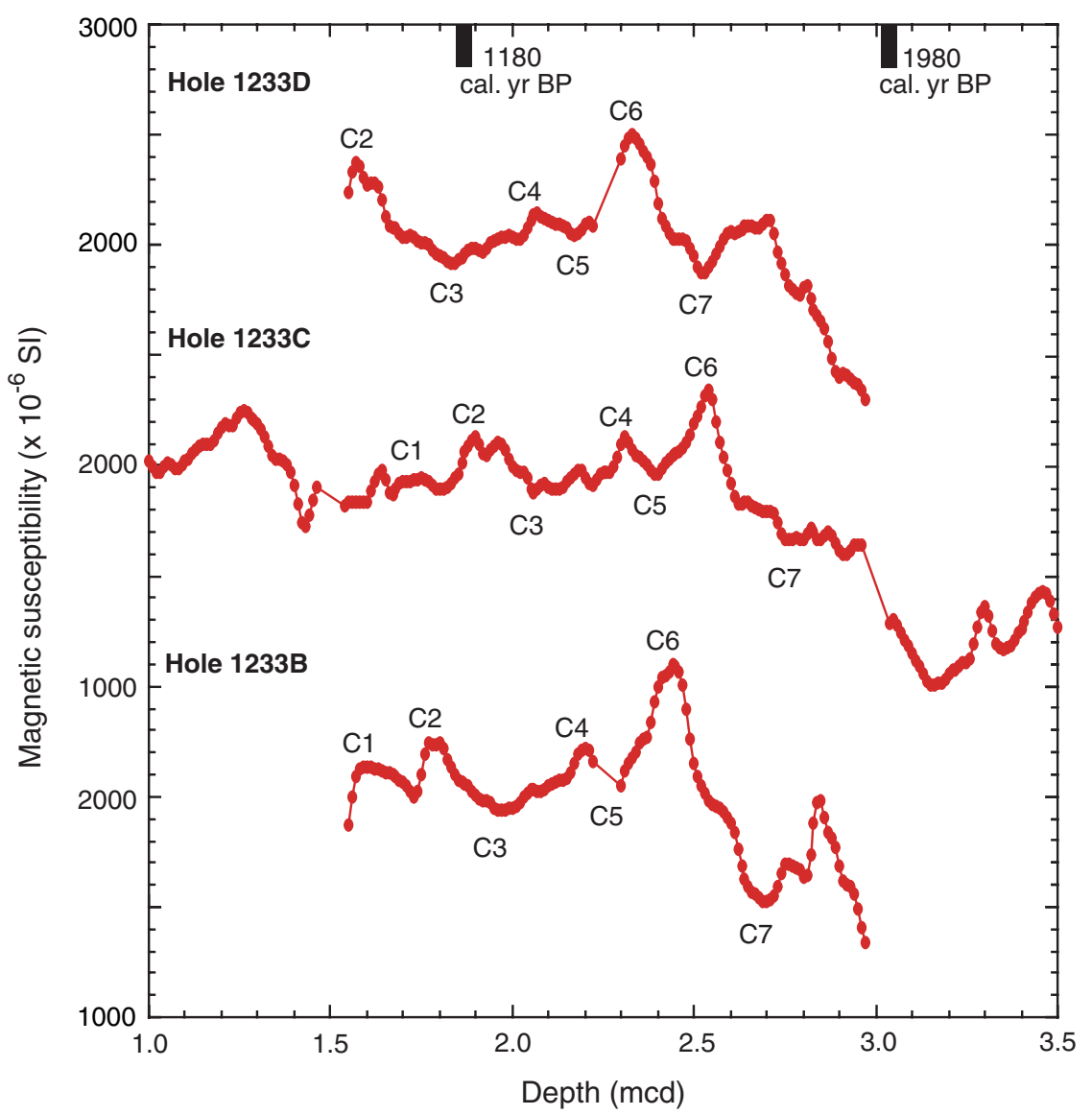


S.P. LUND ET AL.

Paleomagnetic and Rock Magnetic Variability

Figure F2. Stage 1 high-resolution interval 1-cm U-channel initial anhysteretic remanent magnetization (ARM) measurements. Selected correlatable centennial-scale features are labeled A1-A6. mcd = meters composite depth. $\mathrm{BP}=$ before present.

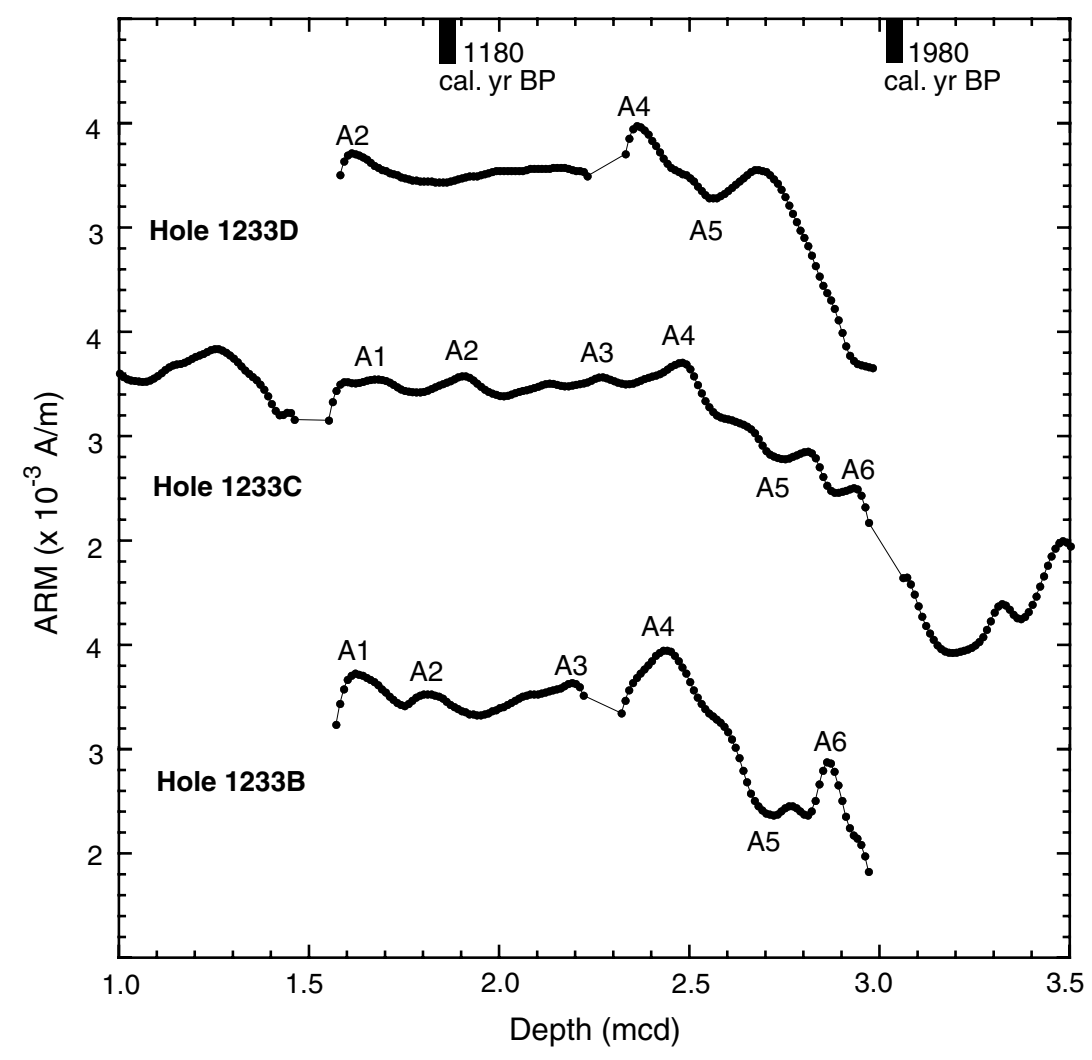


S.P. LUND ET AL.

Paleomagnetic And Rock Magnetic Variability

Figure F3. Solid circles (Hole 1233B) and squares (Hole 1233D) indicate rock magnetic correlations with Hole 1233C as noted in Figures F1, p. 13 and F2, p. 14. If all features occurred at equivalent depths in all cores, the solid circles and squares would all fall on the diagonal solid line. In reality, they do not because of small variations in sediment accumulation that are not accounted for by the meters composite depth (mcd) stratigraphy developed on board the ship (Mix, Tiedemann, Blum, et al., 2003). The solid lines drawn through the circles $(20$-cm boxcar running average) represent an improved, approximately \pm 5 -cm resolution, correlation among the cores. The open symbols indicate paleomagnetic features that are correlatable among the three cores. These features display the same pattern of correlation noted for the rock magnetic parameters.

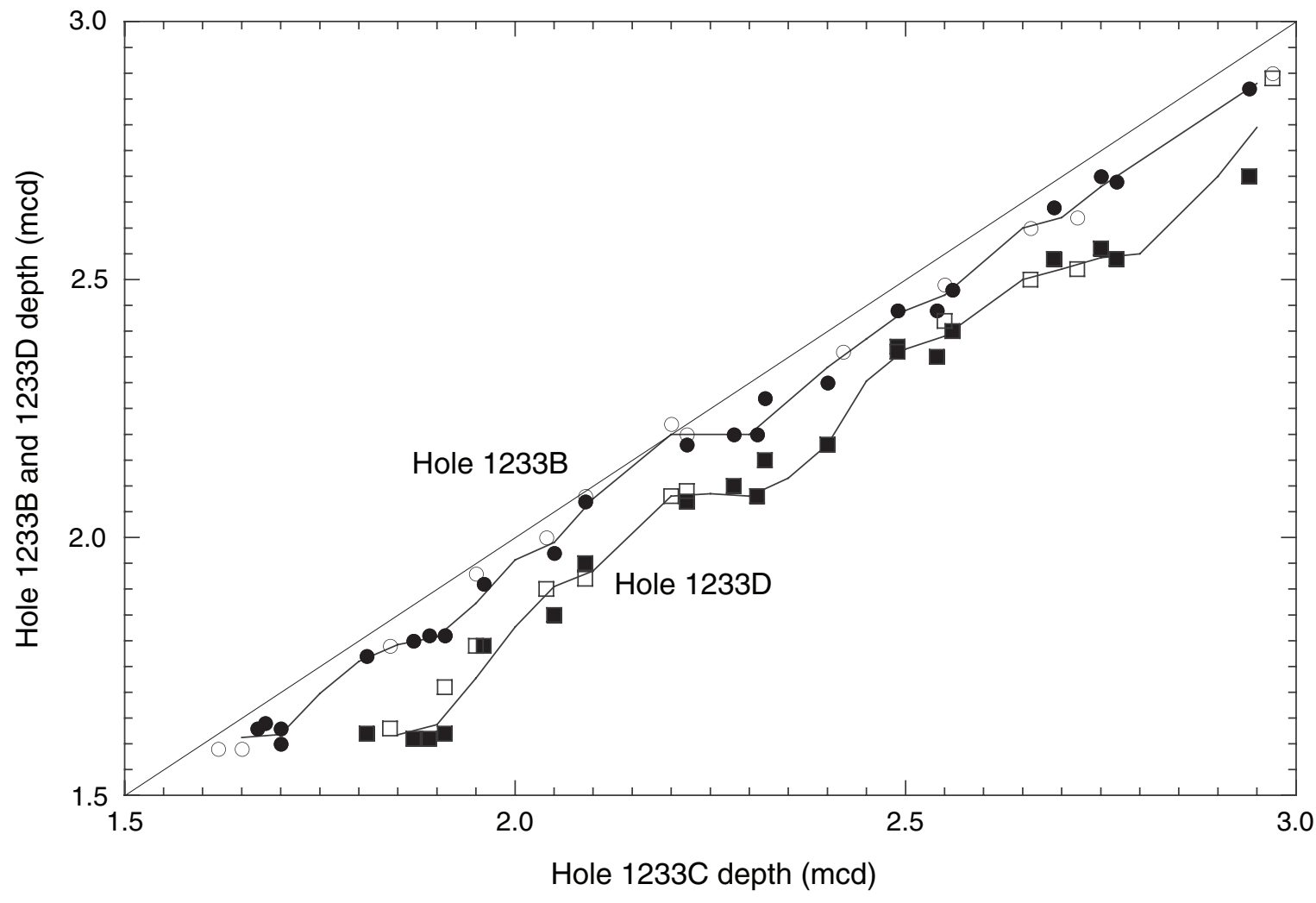


S.P. LUND ET AL.

Paleomagnetic And Rock Magnetic Variability

Figure F4. Stage 1 high-resolution interval paleomagnetic inclination measurements (25 mT AF demagnetization). Solid circles indicate new U-channel (1-cm interval) paleomagnetic measurements. Open diamonds are preliminary shipboard (5- $\mathrm{cm}$ interval) measurements; dashed line is seven-point running average through the shipboard measurements. Millennial-scale inclination features identified from the shipboard measurements (Lund et al., this volume) are indicated by the numbered gray arrows (features 2 and 4 are inclination highs; features 3 and 5 are inclination lows). Selected correlatable centennial-scale inclination features based on U-channel measurements are labeled I1-I8. Black arrows indicate selected nonreproducible features discussed in the text. $\mathrm{mcd}=$ meters composite depth. $\mathrm{BP}=$ before present.

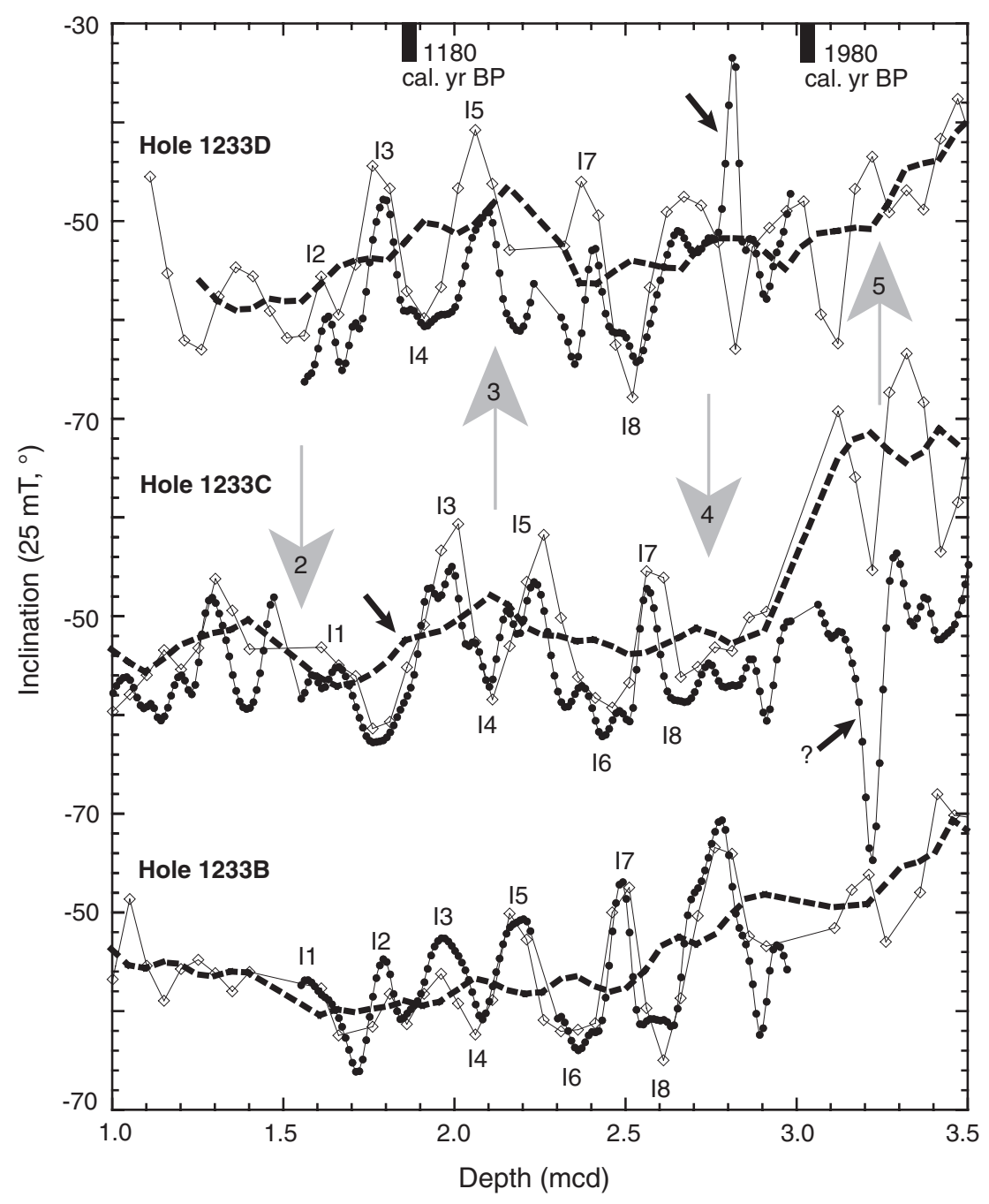


S.P. LUND ET AL.

Paleomagnetic And Rock Magnetic Variability

Figure F5. Stage 1 high-resolution interval paleomagnetic declination measurements ( $25 \mathrm{mT}$ AF demagnetization). Solid circles indicate new U-channel (1-cm interval) paleomagnetic measurements. Open diamonds are preliminary shipboard (5- $\mathrm{cm}$ interval) measurements; dashed line is seven-point running average through the shipboard measurements. Millennial-scale declination features identified from the shipboard measurements (Lund et al., this volume) are indicated by the numbered gray arrows. Selected correlatable centennial-scale declination features based on the U-channel measurements are labeled D1D6. Black arrows indicate selected nonreproducible features discussed in the text. mcd = meters composite depth. $\mathrm{BP}=$ before present.

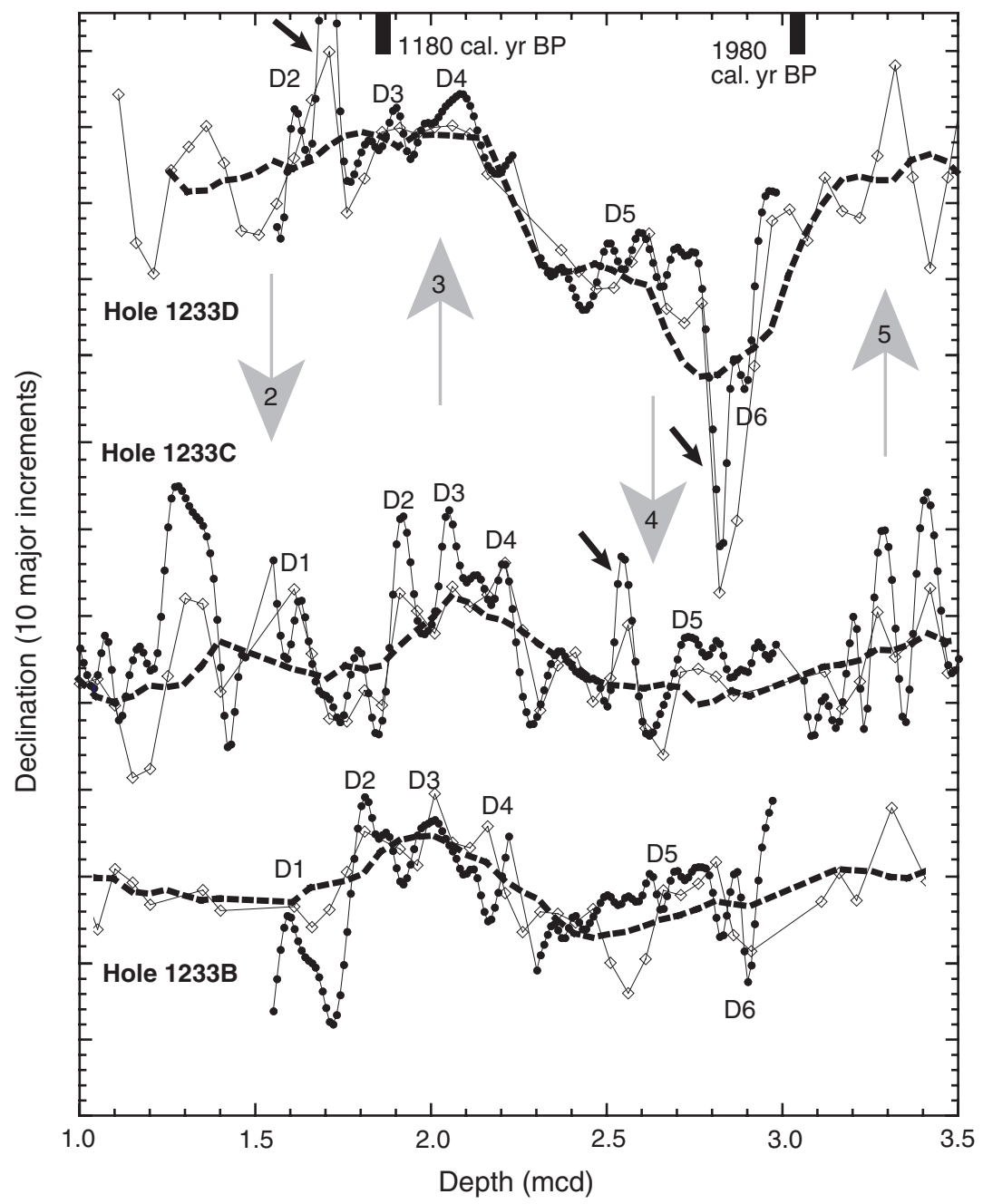


S.P. LUND ET AL.

Paleomagnetic and Rock Magnetic Variability

Figure F6. Stage 2 high-resolution interval U-channel (1-cm interval, solid circles) and preliminary shipboard (5-cm interval, open circles) magnetic susceptibility measurements. Selected correlatable centennialscale features are labeled 1-11. mcd = meters composite depth.

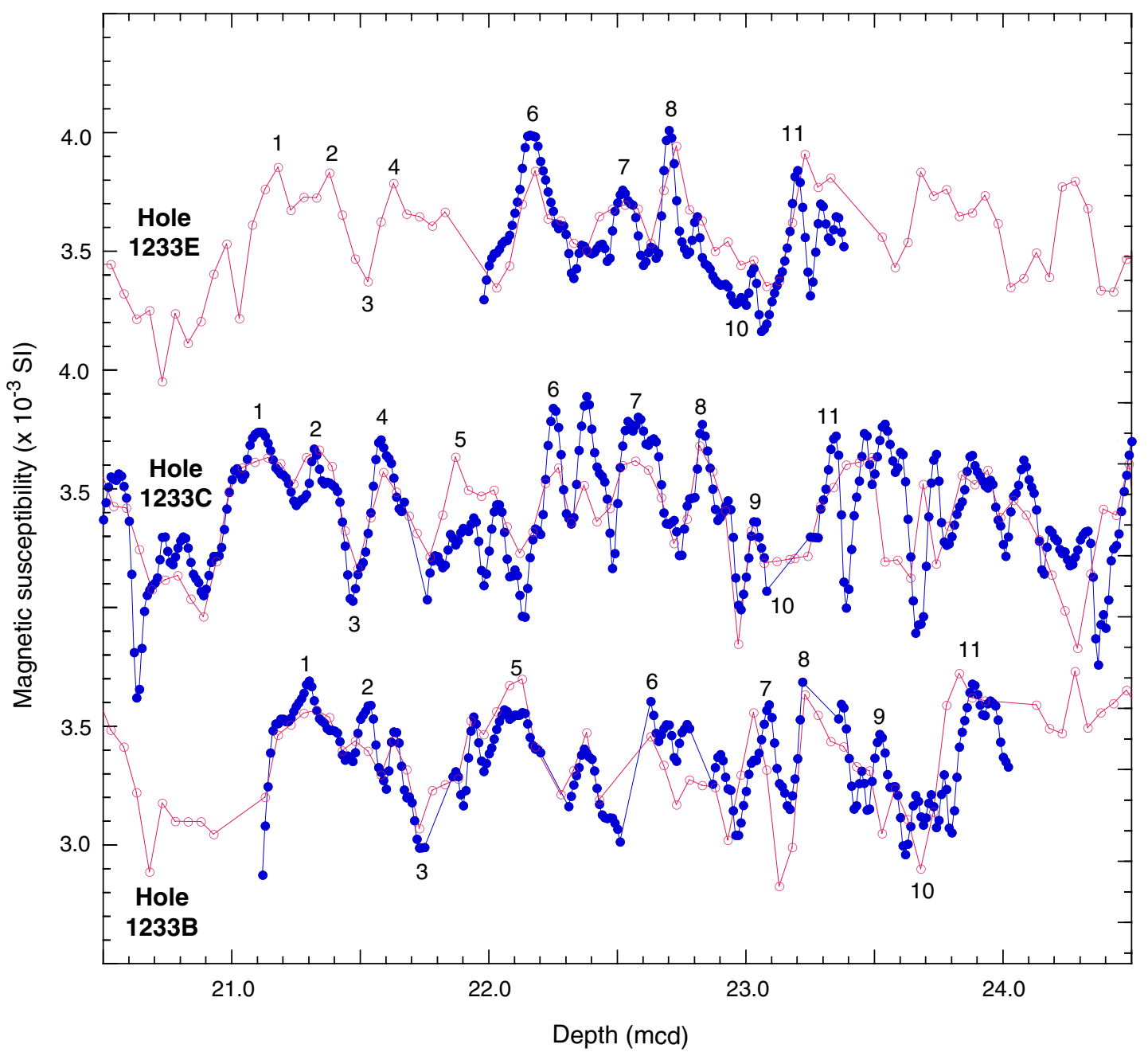


S.P. LUND ET AL.

Paleomagnetic and Rock Magnetic Variability

Figure F7. Stage 2 high-resolution U-channel initial anhysteretic remanent magnetization (ARM) measurements. Selected correlatable centennial-scale features are labeled 1-6. mcd = meters composite depth.

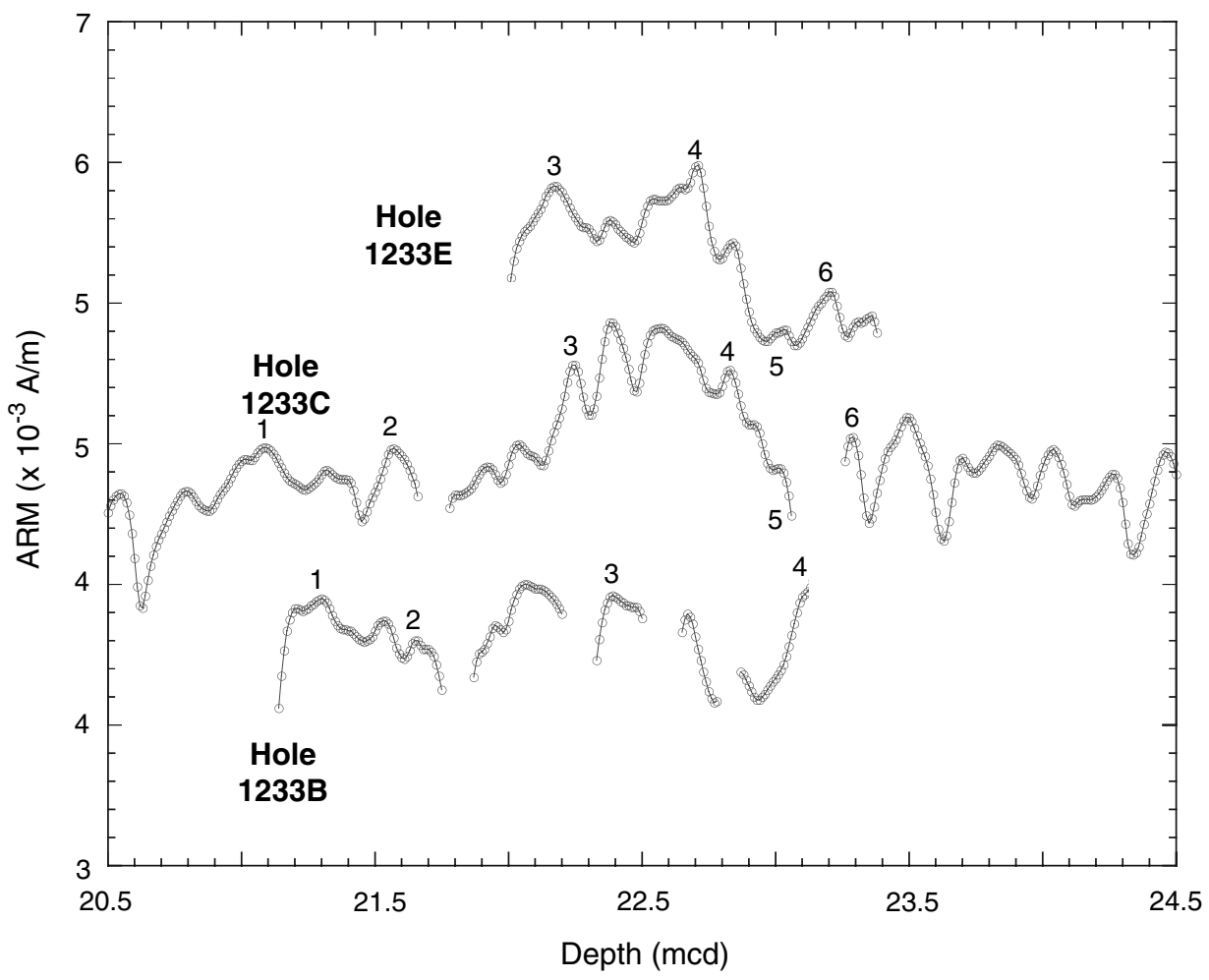


S.P. LUND ET AL.

Paleomagnetic And Rock Magnetic Variability

Figure F8. Solid circles (Hole 1233B) and squares (Hole 1233E) represent rock magnetic features correlatable with Hole 1233C as noted in Figures F6, p. 18 and F7, p. 19. If all features occurred at equivalent depths in both cores the solid symbols would all fall on the diagonal line. In reality, they do not because of small variations in sediment accumulation that are not accounted for by the composite depth stratigraphy developed on board the ship (Mix, Tiedemann, Blum, et al., 2003). The lines (20-cm boxcar running average) drawn through the solid symbols represent an improved, approximately \pm 5 -cm resolution, correlation among the cores. The open symbols indicate paleomagnetic features that are correlatable among the three cores. These features display the same pattern of correlation noted for the rock magnetic parameters. mcd = meters composite depth.

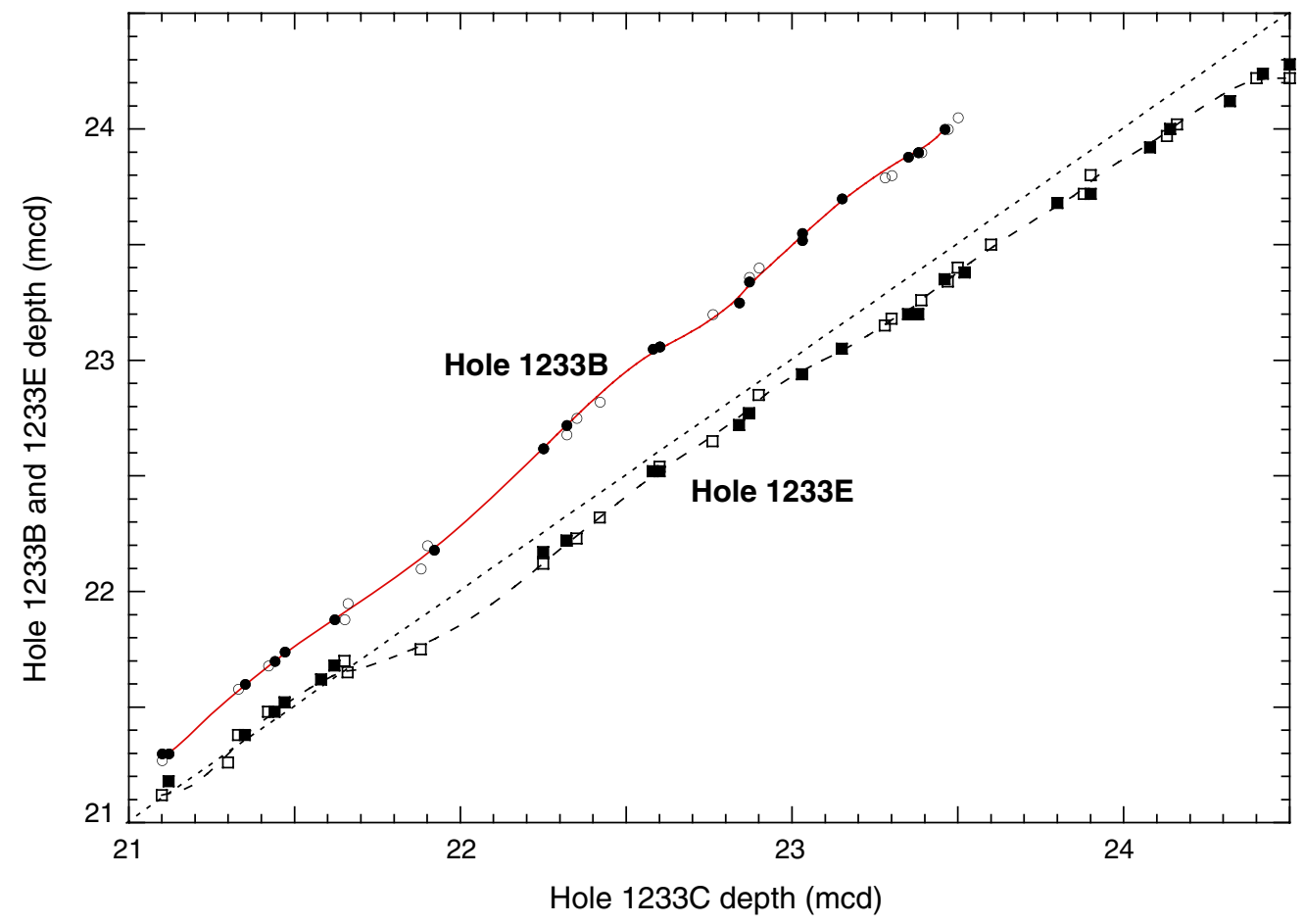


S.P. LUND ET AL.

Paleomagnetic And Rock Magnetic Variability

Figure F9. Stage 2 high-resolution interval paleomagnetic inclination measurements ( $25 \mathrm{mT}$ AF demagnetization). Solid circles indicate new U-channel (1-cm interval) paleomagnetic measurements. Open diamonds are preliminary shipboard (5-cm interval) measurements; dashed line is their seven-point running average. Millennial-scale inclination features identified from the shipboard measurements (Lund et al., this volume) are indicated by the numbered gray arrows (features 22 and 24 are inclination highs; features 23, 23', and 25 are inclination lows). Selected correlatable centennial-scale inclination features based on Uchannel measurements are labeled 1-12. Black arrows indicate selected nonreproducible features discussed in the text. mcd = meters composite depth.

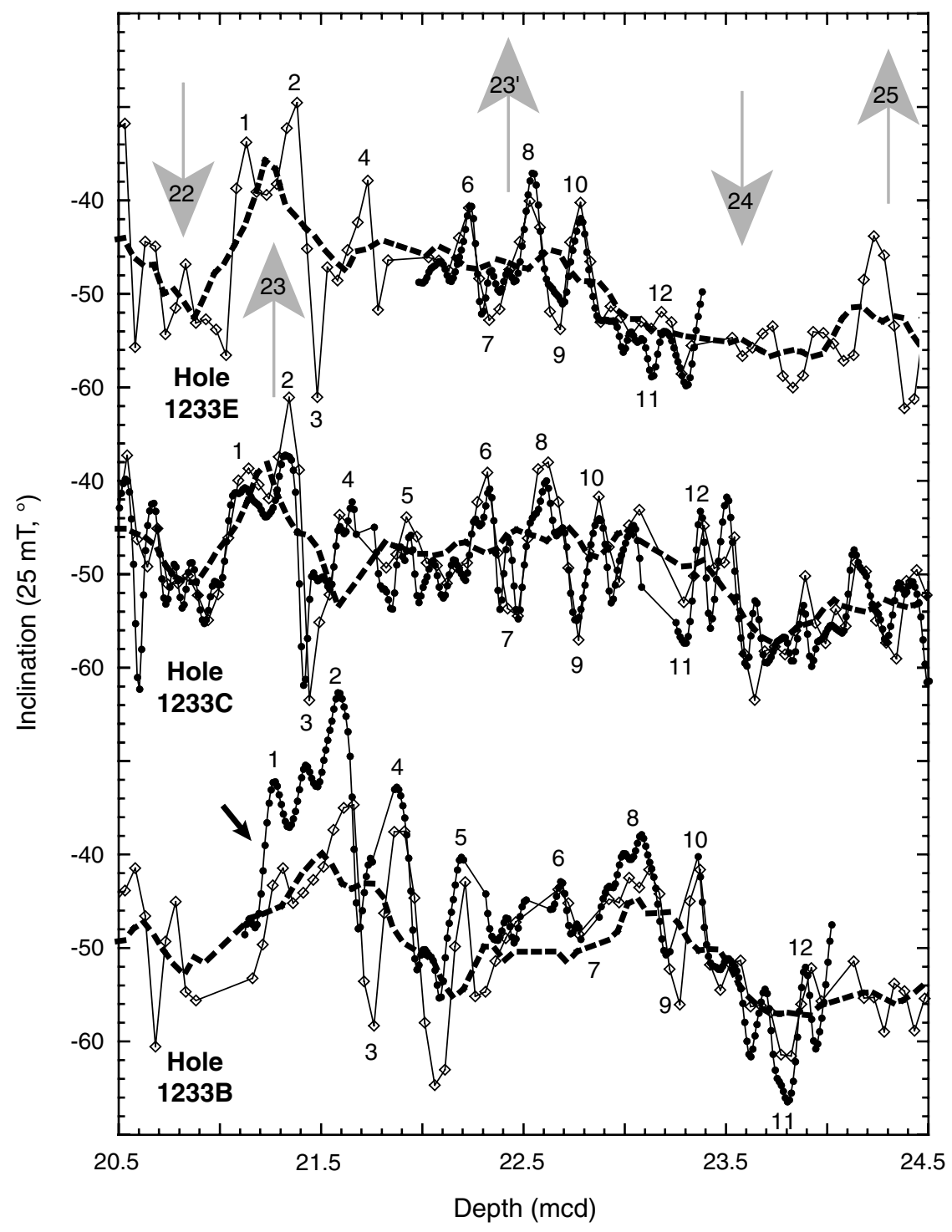


S.P. LUND ET AL.

Paleomagnetic and Rock Magnetic Variability

Figure F10. Stage 2 high-resolution interval paleomagnetic declination measurements (25 mT AF demagnetization). Solid circles indicate new U-channel (1-cm interval) paleomagnetic measurements. Open diamonds are preliminary shipboard (5-cm interval) measurements; dashed line is seven-point running average. Millennial-scale declination features identified from the shipboard measurements (Lund et al., this volume) are indicated by the numbered gray arrows. Selected correlatable centennial-scale declination features are labeled 1-10. mcd = meters composite depth.

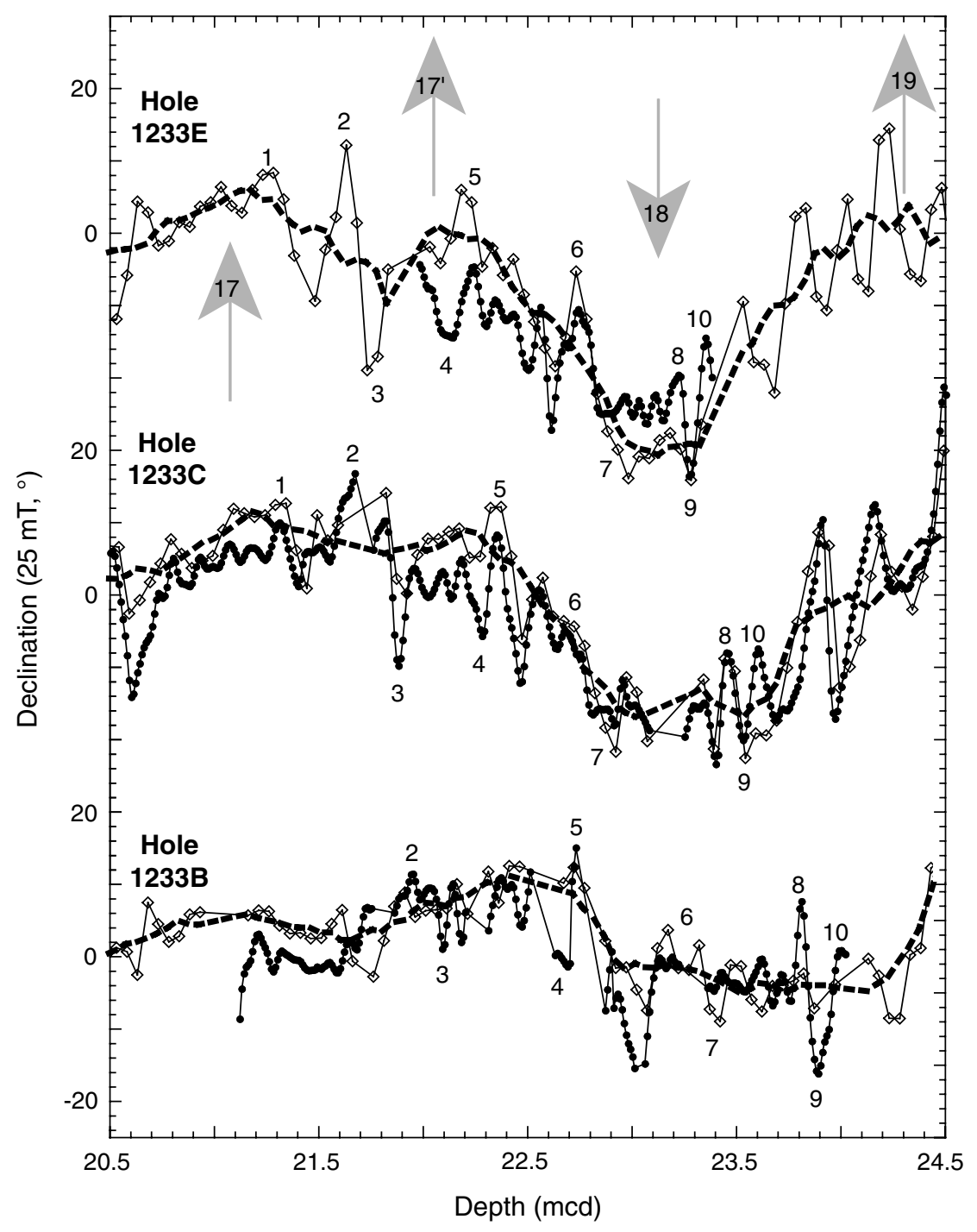


S.P. LUND ET AL.

Paleomagnetic and Rock Magnetic Variability

Figure F11. Stage 3 high-resolution interval U-channel (1-cm interval) magnetic susceptibility measurements. Selected correlatable centennial-scale features are labeled 1-7. mcd $=$ meters composite depth.

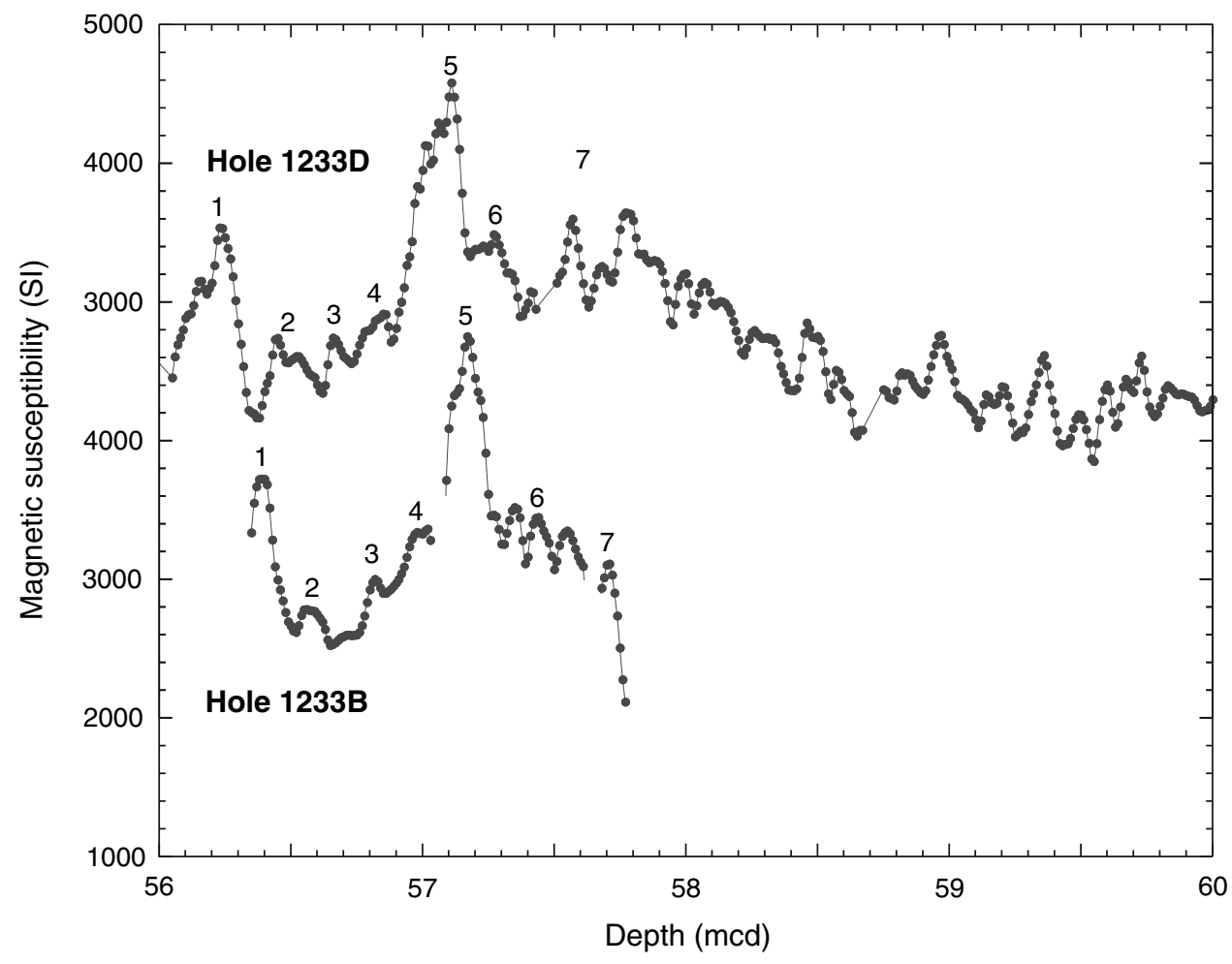


S.P. LUND ET AL.

Paleomagnetic and Rock Magnetic Variability

Figure F12. Stage 3 high-resolution interval U-channel (1-cm interval) initial anhysteretic remanent magnetization (ARM) measurements. Selected correlatable centennial-scale features are labeled 1-7. $\mathrm{mcd}=$ meters composite depth.

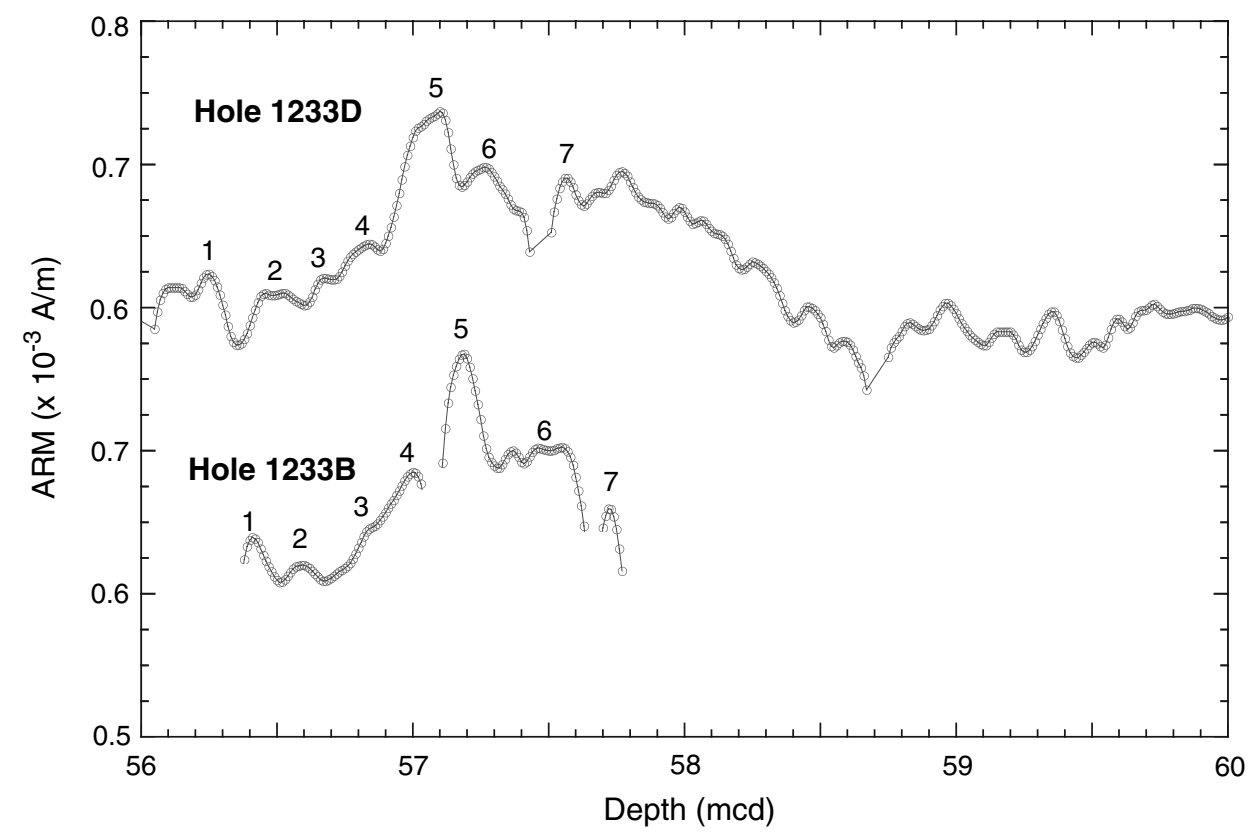


S.P. LUND ET AL.

Paleomagnetic and Rock Magnetic Variability

25

Figure F13. Correlatable rock magnetic features (solid circles) between cores 1233D and 1233B as noted in Figures F11, p. 23 and F12, p. 24. If all features occurred at equivalent depths in both cores the solid circles would all fall on the diagonal solid line. In reality, they do not because of small variations in sediment accumulation that are not accounted for by the composite depth stratigraphy developed on board the ship (Mix, Tiedemann, Blum, et al., 2003). The solid line (20-cm boxcar running average) drawn through the circles represents an improved, approximately $\pm 5-\mathrm{cm}$ resolution, correlation between the cores. The open symbols indicate paleomagnetic features that are correlatable between the two cores. These features display the same pattern of correlation noted for the rock magnetic parameters. mod = meters composite depth.

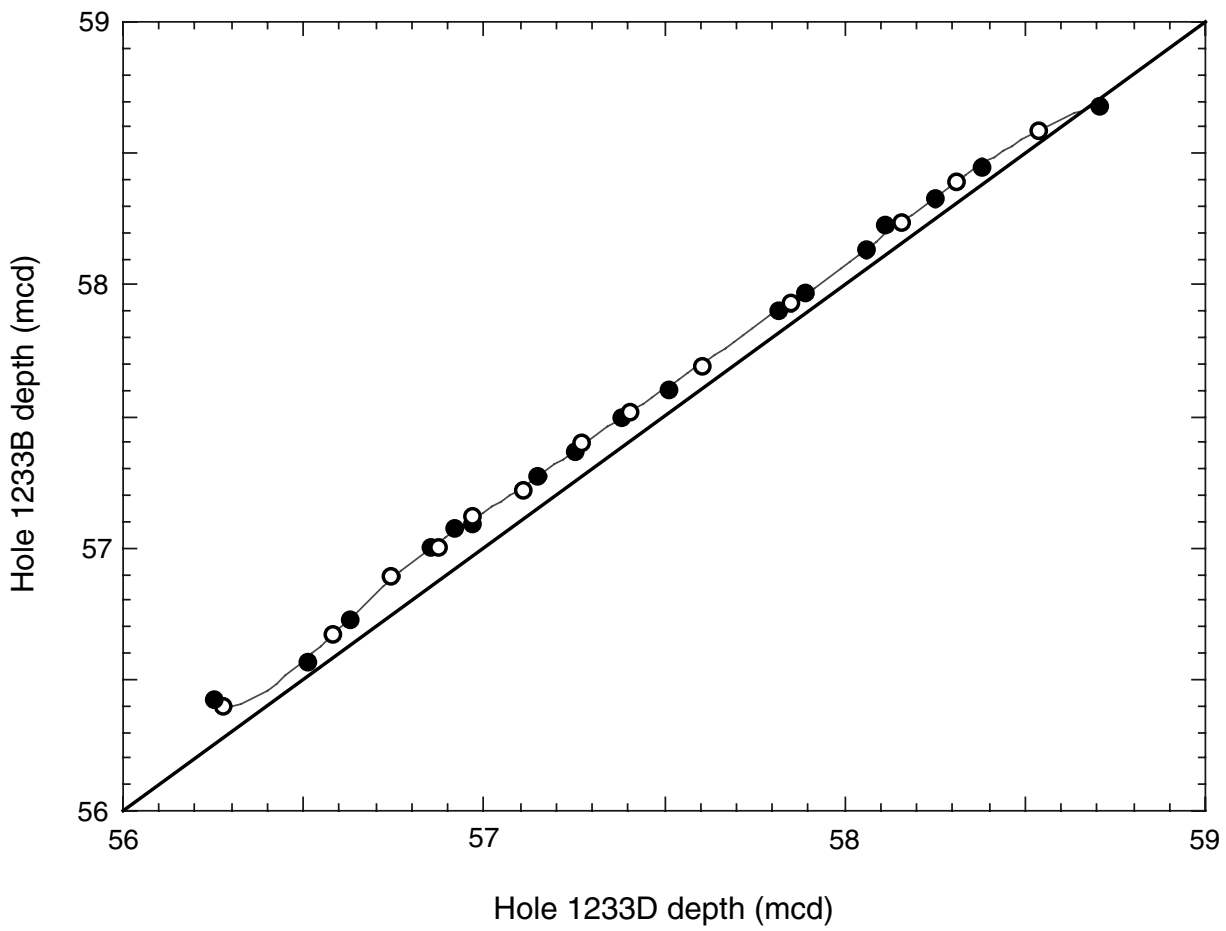


S.P. LUND ET AL.

Paleomagnetic and Rock Magnetic Variability

Figure F14. Stage 3 high-resolution interval paleomagnetic inclination measurements (25 mT AF demagnetization). Solid circles are U-channel (1-cm interval) paleomagnetic measurements. Open diamonds are preliminary shipboard (5-cm interval) measurements; dashed line is seven-point running average. Millennial-scale inclination features identified from the shipboard measurements (Lund et al., this volume) are indicated by the numbered gray arrows. Selected correlatable centennial-scale inclination features are labeled 1-10. $\mathrm{mcd}=$ meters composite depth. $\mathrm{BP}=$ before present.

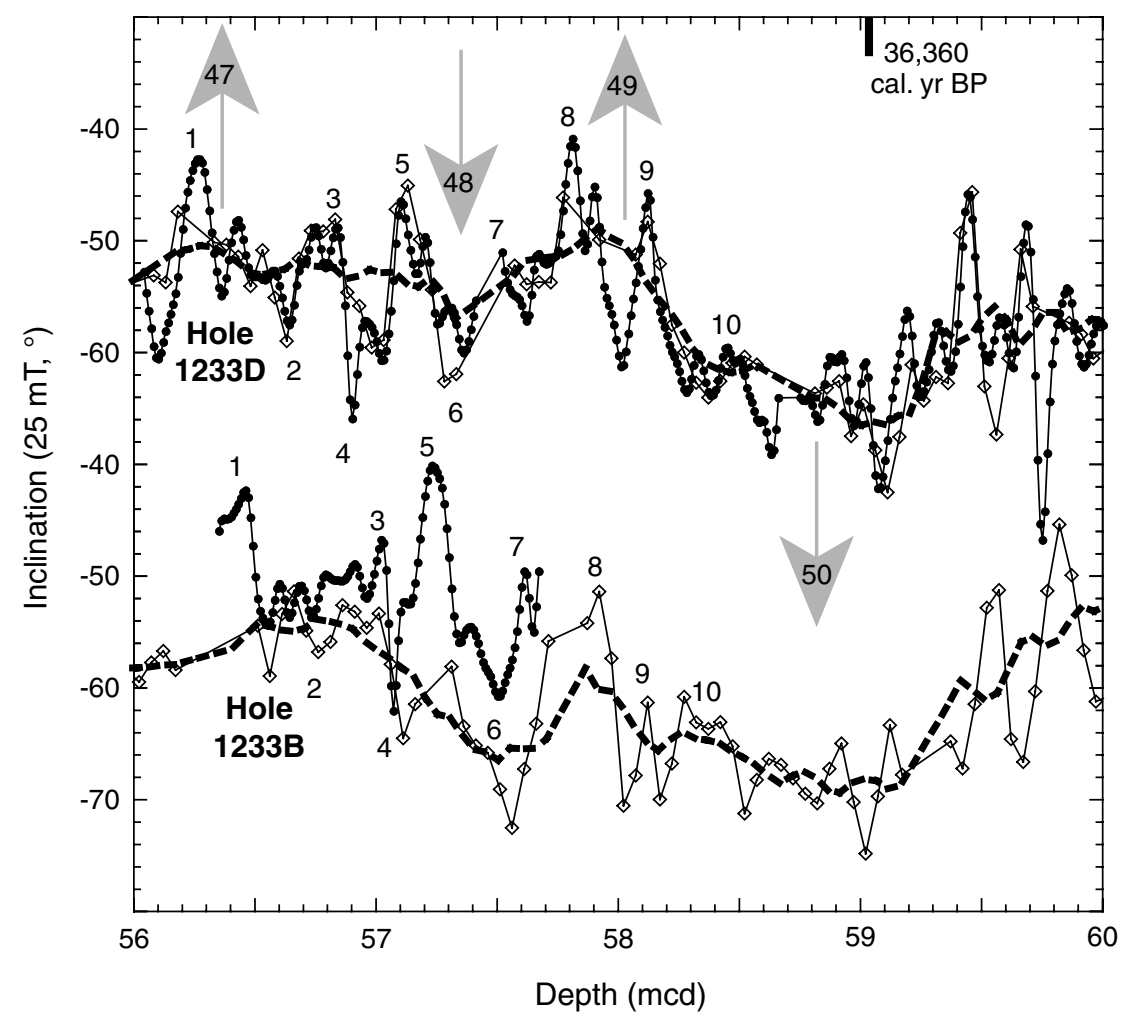


S.P. LUND ET AL.

Paleomagnetic and Rock Magnetic Variability

Figure F15. Stage 3 high-resolution interval paleomagnetic declination measurements (25 mT AF demagnetization). Solid circles are U-channel (1-cm interval) paleomagnetic measurements. Open diamonds are preliminary shipboard (5-cm interval) measurements; dashed line is seven-point running average. Millennial-scale declination features identified from the shipboard measurements (Lund et al., this volume) are indicated by the numbered gray arrows. Selected correlatable centennial-scale declination features are labeled 1-8. mcd = meters composite depth.

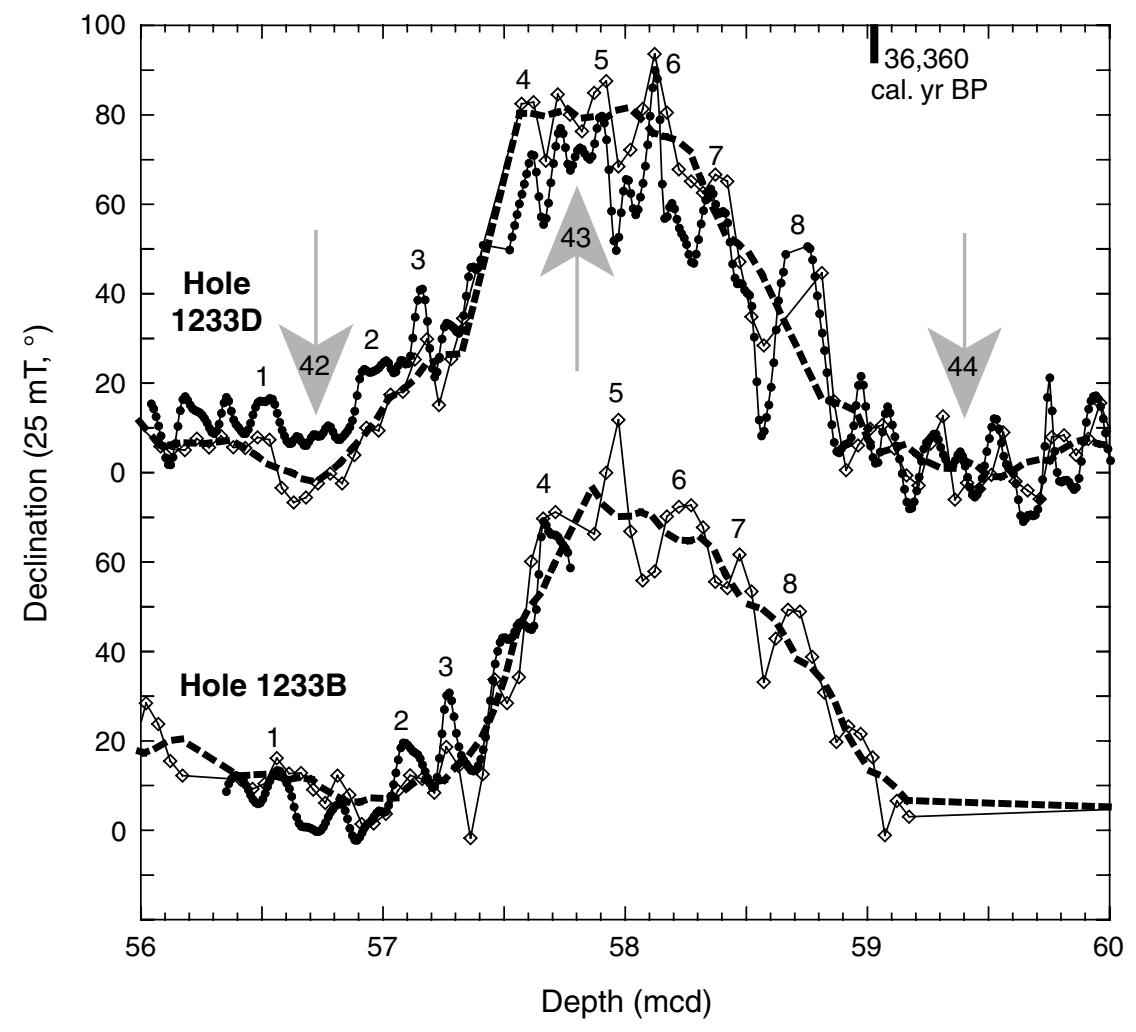


S.P. LUND ET AL.

Paleomagnetic And Rock Magnetic Variability

Figure F16. Comparison of U-channel paleomagnetic results (open circles) from the Stage 1 high-resolution interval with results after data deconvolution (solid dots), both at $25 \mathrm{mT}$ AF demagnetization. Correlatable centennial-scale features are labeled as in Figures F4, p. 16 and F5, p. 17. Arrows indicate two narrow intervals where divergent directions noted in the deconvolution create features that are probably not of geomagnetic origin. mcd $=$ meters composite depth.

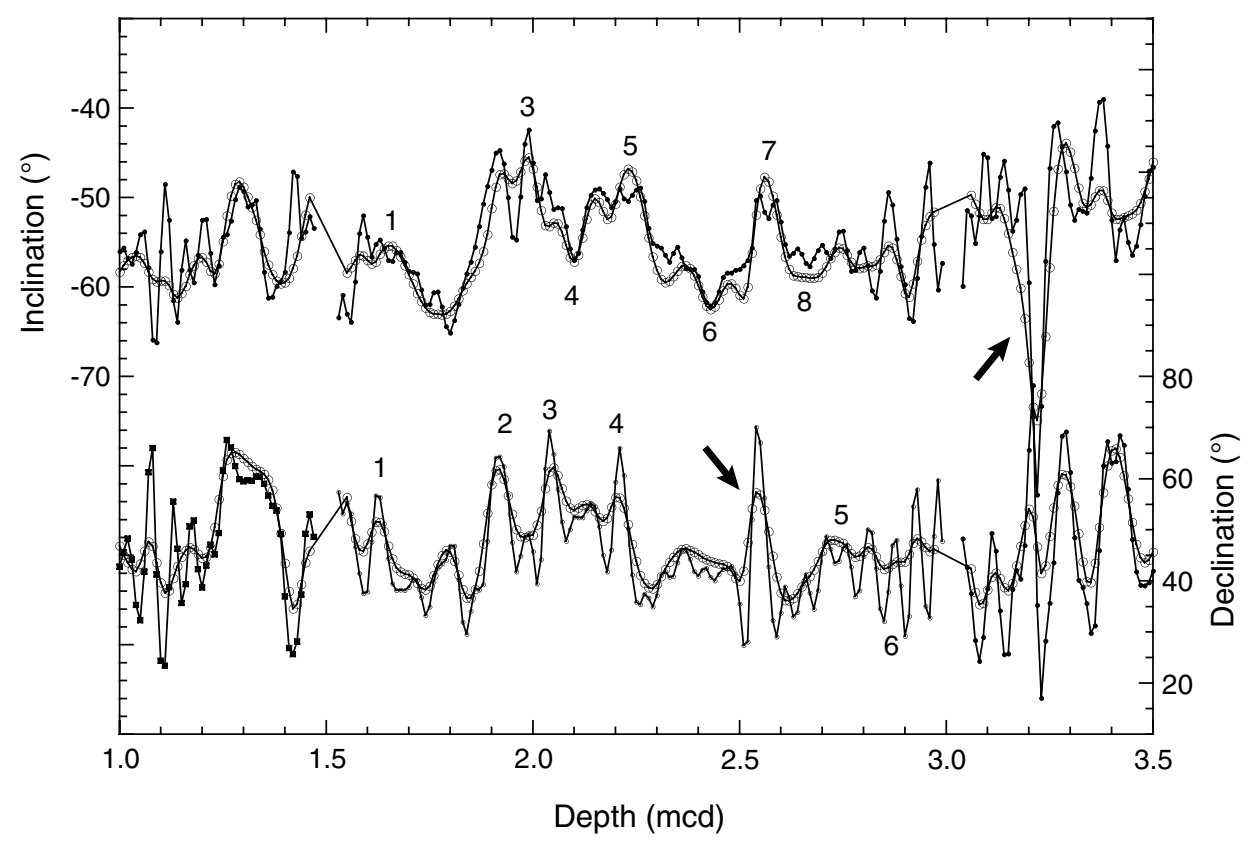


S.P. LUND ET AL.

Paleomagnetic and Rock Magnetic Variability

Figure F17. Comparison of U-channel paleomagnetic results (open circles) from the Stage 2 high-resolution interval with results after data deconvolution (solid dots), both at $25 \mathrm{mT}$ AF demagnetization. Correlatable centennial-scale features are labeled as in Figures F9, p. 21 and F10, p. 22. Arrows indicate three narrow intervals where divergent directions noted in the deconvolution create features that are probably not of geomagnetic origin. mcd = meters composite depth.

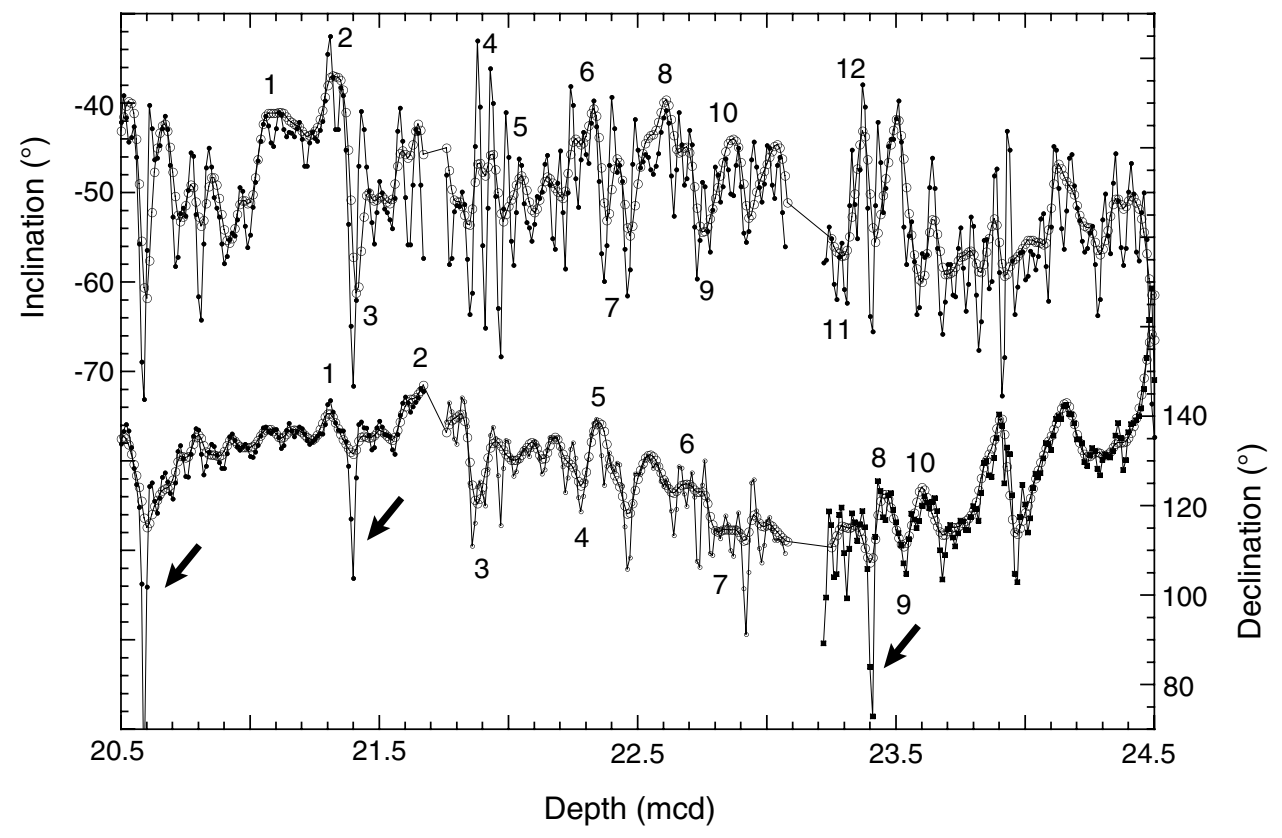


S.P. LUND ET AL.

Paleomagnetic And Rock Magnetic Variability

Figure F18. Comparison of U-channel paleomagnetic results (open circles) from the Stage 3 high-resolution interval with results after data deconvolution (solid dots), both at $25 \mathrm{mT}$ AF demagnetization. Correlatable centennial-scale features are labeled as in Figures F14, p. 26 and F15, p. 27. There is one narrow interval where divergent directions noted in the deconvolution create a feature that is probably not of geomagnetic origin. mcd $=$ meters composite depth.

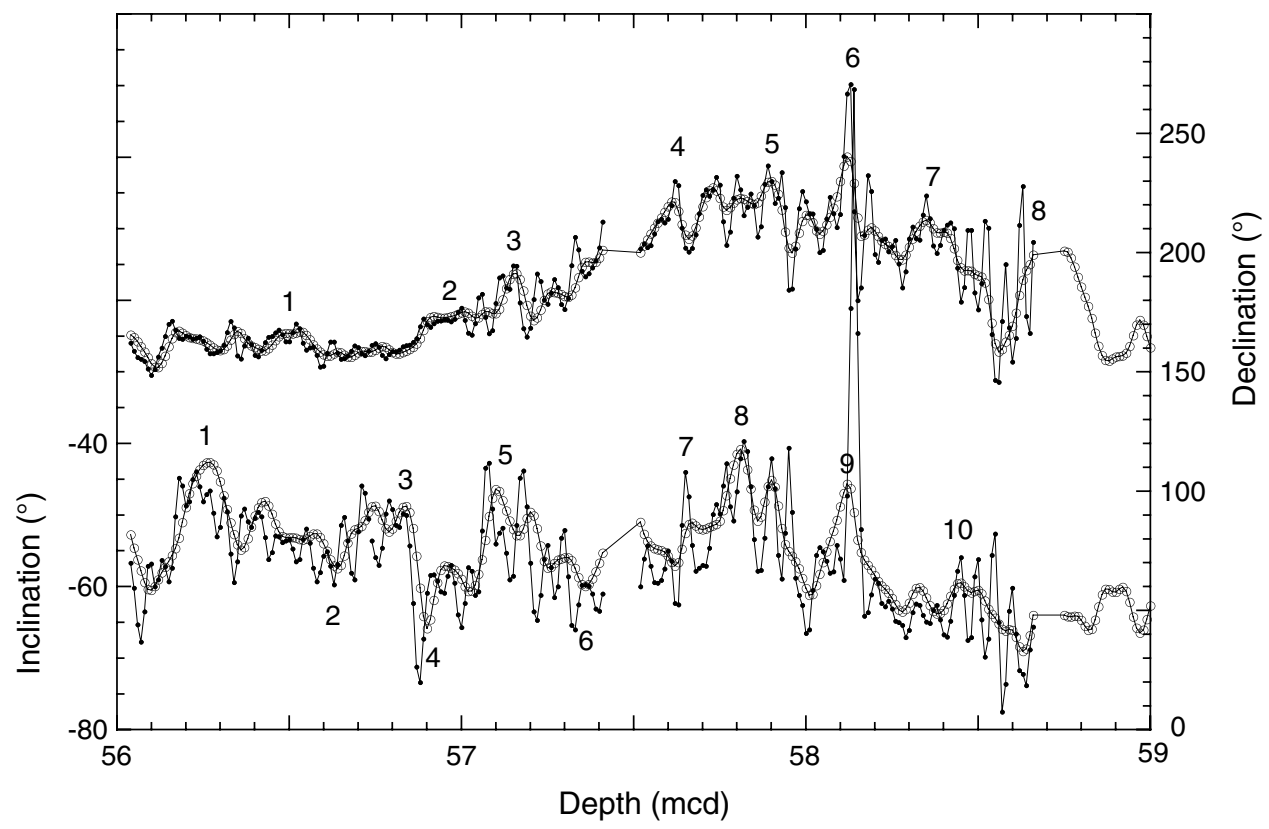

